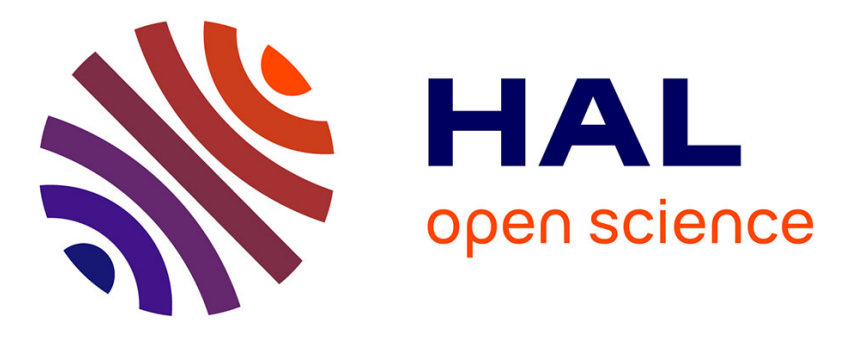

\title{
New Insights into the Structure and Degradation of Alizarin Lake Pigments: Input of the Surface Study Approach
}

Guanzheng Zhuang, Silvia Pedetti, Yoan Bourlier, Philippe Jonnard, Christophe Méthivier, Philippe Walter, Claire-Marie Pradier, Maguy Jaber

\section{To cite this version:}

Guanzheng Zhuang, Silvia Pedetti, Yoan Bourlier, Philippe Jonnard, Christophe Méthivier, et al.. New Insights into the Structure and Degradation of Alizarin Lake Pigments: Input of the Surface Study Approach. Journal of Physical Chemistry C, 2020, 124 (23), pp.12370-12380. 10.1021/acs.jpcc.0c00746 . hal-02887434

\section{HAL Id: hal-02887434 \\ https://hal.sorbonne-universite.fr/hal-02887434}

Submitted on 2 Jul 2020

HAL is a multi-disciplinary open access archive for the deposit and dissemination of scientific research documents, whether they are published or not. The documents may come from teaching and research institutions in France or abroad, or from public or private research centers.
L'archive ouverte pluridisciplinaire HAL, est destinée au dépôt et à la diffusion de documents scientifiques de niveau recherche, publiés ou non, émanant des établissements d'enseignement et de recherche français ou étrangers, des laboratoires publics ou privés. 
New insights into the structure and degradation of alizarin lake pigments: input of the surface study approach

Guanzheng Zhuang a,b,c Silvia Pedetti a , yoan Bourlier a, Philippe Jonnard d, Christophe Méthivier ${ }^{\mathrm{e}}$, Philippe Walter ${ }^{\mathrm{a}}$, Claire-Marie Pradier ${ }^{\mathrm{e}}$ and Maguy Jaber ${ }^{\mathrm{a}, *}$ a Sorbonne Université, Laboratoire d'Archéologie Moléculaire et Structurale (LAMS), CNRS UMR 8220, Paris, France.

${ }^{\mathrm{b}}$ CAS Key Laboratory of Mineralogy and Metallogeny, Guangzhou Institute of Geochemistry, Chinese Academy of Sciences, Guangzhou 510640, China.

c Guangdong Provincial Key Laboratory of Mineral Physics and Materials, Guangzhou 510640, China.

d Sorbonne Université, Laboratoire de Chimie Physique-Matière et Rayonnement (LCPMR), CNRS UMR 7614, Paris, France.

e Sorbonne Université, Laboratoire de réactivité des surfaces (LRS), CNRS UMR 7197, Paris, France.

Corresponding Author:

Maguy Jaber

Email: maguy.jaber@upmc.fr 
Abstract

Alizarin (Az) lake is a typical example of lake pigments that is widely used in cultural heritages. Previous work focused on the complex formation in solution, theoretical models and crystallized stoichiometric complexes. The real nature of lake pigments, as well as the reason for its degradation, are still controversial. In this work, we prepared the Az lakes from the ancient recipe with non-stoichiometric complexes, i.e., $\mathrm{R}=5-200\left(\mathrm{R}\right.$ refers to molar ratio of $\mathrm{Al}^{3+} / \mathrm{Az}$ ). The influences of the dye concentration, $\mathrm{pH}$ and basic reagents on the structures and chromatic properties of bulk Az lakes were studied by attenuated total reflection Fourier transform infrared spectrum (ATR-FTIR), nuclear magnetic resonance (NMR) and CIE 1976 color space. In order to investigate the surfaction between $\mathrm{Az}$ and the alumina inorganic substrate, likely determining in the aging of pigments, Az was deposited on a thin $\mathrm{Al}_{2} \mathrm{O}_{\mathrm{x}}$ film prepared by physical vapor deposition method. Polarization modulation infrared reflection absorption spectroscopy (PM-IRRAS) was employed to characterize the chemical reactivity and degradation of $\mathrm{Az}-\mathrm{Al}_{2} \mathrm{O}_{\mathrm{x}}$ film complex. $\mathrm{Az}$ derivatives interacted with $\mathrm{Al}_{2} \mathrm{O}_{\mathrm{x}}$ film like bulk lakes. $\mathrm{Al}^{3+}$ were coordinated with 1,2-dihydroxyl (catechol) group, instead of 1-hydroxy-9-keto group. Exposure under UV light resulted in degradation of $\mathrm{Az}-\mathrm{Al}_{2} \mathrm{O}_{\mathrm{x}}$ film complex by oxidizing catechol groups to carbonyl. This study presented a new insight into the structure and degradation of Az lake.

Keywords: Lake pigments, Alizarin, Photostability, $\mathrm{Al}_{2} \mathrm{O}_{\mathrm{x}}$ film, UV light. 


\section{Introduction}

The growing attention in the study of art objects for the purposes of conservation and restoration has raised much interest in investigating the structure and physical-chemical properties of the materials used in art works[1]. Particularly, organic dyes and pigments are key components in cultural heritage artifacts, such as easel paintings, polychrome arts, manuscript illuminations, textiles, etc. Since color is an important component in the perception of beauty and in an artist's original intent when creating a work, better conservation of the cultural heritage requires detailed knowledge of dyes and pigments, including the complex evolution they have endured over time[2].

Both dyes and pigments have distinct features: dyes are soluble in the medium in which they are present, while pigments are solid state[3]. But organic dyes can be fixed on inorganic substrates to build organic-inorganic hybrid pigments, which sometimes exhibit remarkable stability. Lake pigments[2, 4-6] and Maya blue[7-9] are the typical hybrid pigments prepared from natural dyes and inorganic substrates. Particularly, a famous red lake, known as madder lake, was used for painting by precipitating the madder dyestuffs (extracted from the roots of Rubia tinctorum L) with a metal salt to form insoluble metal complexes since antiquity[10, 11]. According to historical recipes, the most frequently used metal cation was $\mathrm{Al}^{3+}$, added to the dyestuff as a potassium double sulphate $\left(\mathrm{KAl}\left(\mathrm{SO}_{4}\right)_{2} \cdot 12 \mathrm{H}_{2} \mathrm{O}\right.$, called alum)[12]. 
Alizarin (Az, see Fig. 1), the main component of madder dyestuffs, has been classified among the organic dyes most resistant to light-induced fading, although degradation still happens[13]. Az lake is often considered as a typical example of lake pigments to investigate the formation [14], spectral properties[1, 2, 5, 11, 12, 15-20] and lightfastness[21-24] by using modern and complementary technologies, such as gas chromatography, mass spectrometry, UV-visible spectrophotometry, thin layer chromatography, high performance liquid chromatography.<smiles>O=C1c2ccccc2C(=O)c2c1ccc(O)c2OCO</smiles><smiles>O=C1c2ccccc2C(=O)c2c1ccc([O-])c2O[Tl]O</smiles><smiles>O=C1c2ccccc2C(=O)c2c1ccc([O-])c2O[TlH]</smiles><smiles>O=C1c2ccccc2C(=O)c2c1ccc([O-])c2[O-]</smiles>

Fig. 1 The structure and ionization process of $\mathrm{Az}$ in aqueous solution

In 1920s, Weiser and Porter [25-27] pointed out that the lake formation is due to the adsorption of the Az anion by the hydrous oxides in varying amounts depending on the composition of the dye bath. Later, Kiel and Heertjes stated that the formula of the calcium-aluminum lake of $\mathrm{Az}$ (Turkey Red), i.e., $\mathrm{Ca}_{2} \mathrm{Al}_{3} \mathrm{Az}_{4}$ (where $\mathrm{Az}$ represents an alizarin molecule minus two hydroxylic hydrogen atoms), was wrong. Therefore, 
they carried out a further study of this complex, and they illustrated the formula of the water-containing calcium-aluminum lake of $\mathrm{Az}$ is $\mathrm{CaAl}(\mathrm{OH})(\mathrm{Az})_{2} \cdot x \mathrm{H}_{2} \mathrm{O}$ [4]. The extremely slow reaction of alizarin with the chelate-forming metal aluminum alone due to the strong hydrogen bond between the $1-\mathrm{OH}$ group and the $9-\mathrm{C}=\mathrm{O}$ group. This hydrogen bond has to be broken or at least weakened when a complex was formed. This phenomenon occurred when salt formation $\left(2-\mathrm{OH} \rightarrow 2-\mathrm{O}^{-}\right)$takes place before chelate formation [28]. The other similar Az lakes were also investigated by Kiel and Heertjes [29, 30].

In the beginning of the $21^{\text {st }}$ century, the electronic structure of $\mathrm{Az}$ with eleven different transition metal complexes and five rare-earth complexes were studied using density functional theory (DFT) by Komih et al. [31]. The M-O (M refers to the metal cation) bonds involve $p$ or $d$ metal orbitals depending on whether the $d$ shell is full or empty. The complexation effect leads to a red shift and hence to a color change of the solutions of the complexes. Theoretical calculation also demonstrated that complexation always occurs at the peri- or ortho-hydroxycarbonyl group and involves the tautomeric anthraquinoid forms [32].

Fain et al. (1996) [33] illustrated Az lake as two types of structure based on the ${ }^{27} \mathrm{Al}$ NMR spectra, named "closed structure" (with strongly chelated $\mathrm{H}_{2} \mathrm{O}$ molecules and dibenzene sandwich $\mathrm{Na}^{+}$) and “open structure". Doskocz et al. (2009) [34] pointed out that $\mathrm{Az}$ acted as a bidentate ligand on forming complexes with metal ions based on the ${ }^{1} \mathrm{H}$ and ${ }^{13} \mathrm{C}$ NMR spectra results. The complex structure with the metal attached to two hydroxyl oxygen atoms was of lower energy. Wunderlich and 
Bergerhoff [35] proposed a different structure in which the $\mathrm{Al}^{3+}$ cations coordinated with two Az molecules through the ortho-hydroxyl groups ( $\alpha$-diol position), forming a five-membered chelate cycle, and calcium ions complete the structure, coordinating two dye molecules in the $\beta$-ketol position. The recent investigation on the complexation reaction of Az, which had been carried out by Sanyova in 2001 [36] and 2008 [37], provided experimental evidence in favor of the $\beta$-ketol position of the dye as complexation site. In addition, his research also put forward the hypothesis of possible further aggregation of the complexes through $\mathrm{Al}-\mathrm{O}-\mathrm{Al}$ bonds and cross-linking.

Although much progress about the complex structure had been made in the past decades, the structure of Az lake and the nature of established chemical interactions are still a matter of controversy. Previous works only focused on the complex formation in solution, theoretical models and crystallized stoichiometric complexes. For example, the commercial lake pigments contained very low Az while the stoichiometric investigation always considered the complex structure with the $\mathrm{Az} / \mathrm{Al}^{3+}$ ratio of $1: 1$ and $2: 1[28,32]$. The structure and properties of a real Az lake pigment, with a very low content of Az dye, have never been studied.

What is more important, understanding the degradation pathway of Az lake is a crucial issue for the conservation and restoration of artworks which contain lake pigments. But it is difficult to evaluate the photostability and chemical changes of $\mathrm{Az}$ lake powders during light exposure. Dworak et al. (2009)[38] tried to investigate the photoinduced dynamics of $\mathrm{Az}$ in $\mathrm{Al}_{2} \mathrm{O}_{3}$ and $\mathrm{TiO}_{2}$ mesoporous films that strongly 
coupled with Az. Although the thickness of these films exceeded $1 \mu \mathrm{m}$, their research suggested that the interaction between $\mathrm{Az}$ and aluminum oxides might be an efficient way to study the structure and interaction of Az lake under light exposure. Aluminum oxides $\left(\mathrm{Al}_{2} \mathrm{O}_{\mathrm{x}}\right)$ exhibit the similar coordination with $\mathrm{Al}^{3+}$ complex in basic solutions. The use of $\mathrm{Al}_{2} \mathrm{O}_{\mathrm{x}}$ thin film to study the interaction between $\mathrm{Az}$ and $\mathrm{Al}^{3+}$ presents two essential advantages. First, $\mathrm{Al}_{2} \mathrm{O}_{\mathrm{x}}$ may be under the form of ultrathin layers and permit to investigate the interaction at the molecular scale. Previous quartz crystal microbalance measurements have demonstrated highly uniform layer-by-layer growth of the alumina on $\mathrm{Ag}$ nanoparticles with a growth rate of $\sim 0.1 \mathrm{~nm}$ per deposition per second [39]. The sub-1-nm thickness is extremely advantageous in preserving integrity of the solid and increasing contact area and reactivity. In addition, the ultrathin film of alumina deposited on a reflective surface should enhance the sensitivity and accuracy of spectrometry [40], because only the surface atoms can react with $\mathrm{Az}$ molecules while the internal (bulk) atoms do not. In addition, polarization modulation infrared reflection absorption spectroscopy (PM-IRRAS) can be employed, with a very high sensitivity, to investigate the interfacial interaction between $\mathrm{Az}$ dye and $\mathrm{Al}_{2} \mathrm{O}_{\mathrm{x}}$ thin film.

Aiming to investigate the structures and interactions of Az lake pigments, a series of bulk Az lakes were prepared. The influence of dye concentration, $\mathrm{pH}$ and basic reagents on the structures and chromatic properties has been investigated. In addition, $\mathrm{Az}$ molecules were deposited onto $\mathrm{Al}_{2} \mathrm{O}_{\mathrm{x}}$ thin film prepared by physical vapor deposition (PVD) method. The interaction between $\mathrm{Az}$ and $\mathrm{Al}_{2} \mathrm{O}_{\mathrm{x}}$ thin film and 
the influence of ultraviolet light on the degradation of $\mathrm{Az}-\mathrm{Al}_{2} \mathrm{O}_{\mathrm{x}}$ film complex have also been highlighted.

2 Materials and methods

\subsection{Materials}

$\mathrm{Az}(97 \%), \quad \mathrm{KAl}\left(\mathrm{SO}_{4}\right)_{2} \cdot 12 \mathrm{H}_{2} \mathrm{O}(98 \%), \mathrm{K}_{2} \mathrm{CO}_{3}(98 \%)$ and $\mathrm{KOH}(99 \%)$ were purchased from Sigma-Aldrich, Inc, France. These materials were used without further purification.

\subsection{Preparation of bulk lake pigments}

The lake pigments were prepared as the following procedure: $\mathrm{KAl}\left(\mathrm{SO}_{4}\right)_{2}$ (alum) was dissolved into water with the concentration of $0.5 \mathrm{~mol} / \mathrm{L} ; \mathrm{Az}$ was dissolved into water with the concentration of $0.005 \mathrm{~mol} / \mathrm{L}(\mathrm{pH}=10)$; Az solution was added into alum solution with the molar ratio of $\mathrm{Al} / \mathrm{Az}$ ( $\mathrm{R}$ value) from 5 to 200; a basic reagent $\left(\mathrm{KOH}\right.$ or $\mathrm{K}_{2} \mathrm{CO}_{3}, 0.5 \mathrm{~mol} / \mathrm{L}$ ) was added into the previous solution dropwise after 10 min stirring; The addition was stopped when $\mathrm{pH}$ value reached at 5.5, 6.5, 7.5 and 8.5 corresponding to different speciation states of Az; The solution was stirred for $30 \mathrm{~min}$ and then stood for $12 \mathrm{~h}$; finally, the precipitate was filtered out, washed 3 times and dried at $50^{\circ} \mathrm{C}$ for $24 \mathrm{~h}$.

\subsection{Preparation of aluminum oxide films}

Preparation of aluminum oxide thin films was performed by physical vapor deposition (PVD) and a scheme of the apparatus is shown in Fig. 2(A) (details can be seen in reference [41]). An Al foil, source of $\mathrm{Al}$ atoms, was placed on a tungsten 
filament connected to a DC power supply. Au thin film of $1 \times 1 \mathrm{~cm}^{2}$ and few hundreds of nm thickness on a glass substrate were exposed to flame for three times before use. The $\mathrm{Au}$ substrate was placed in the vacuum chamber equipped with a quartz crystal microbalance placed laterally. Once the sample was inserted into the chamber, the vacuum was maintained for $2 \mathrm{~h}$ to reach a pressure of $10^{-3} \mathrm{~Pa}$. Then the current was slowly increased to a few tens of A to allow $\mathrm{Al}$ evaporation and condensation on the $\mathrm{Au}$ film. The $\mathrm{Al}$ thin film was oxidized in air and $\mathrm{Al}_{2} \mathrm{O}_{\mathrm{x}}$ thin film was formed.
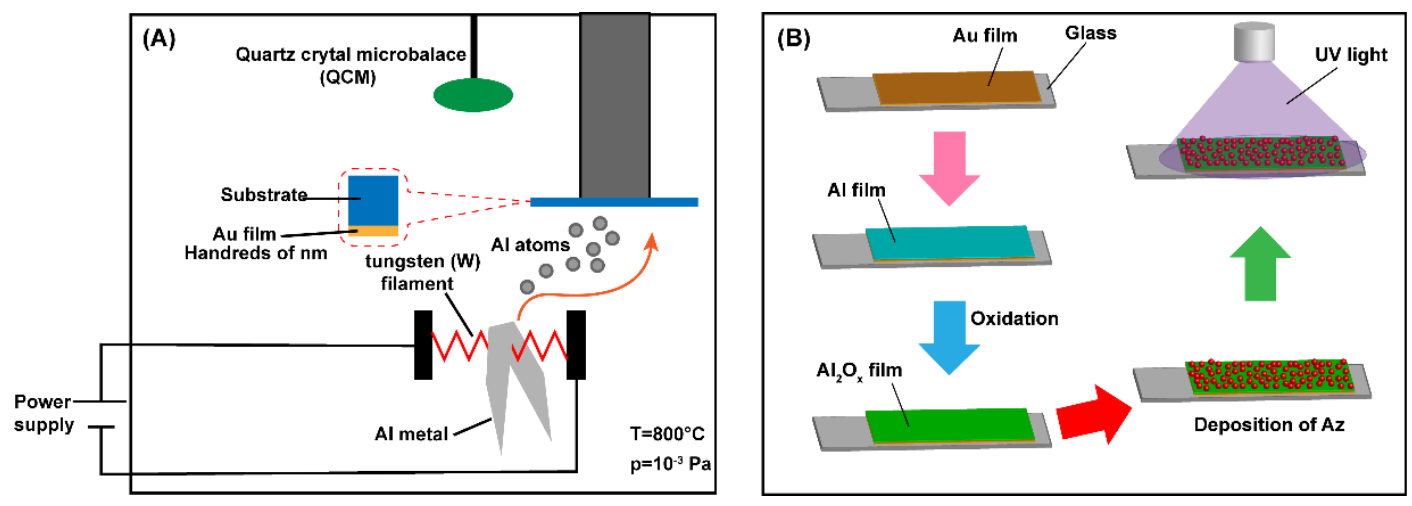

Fig. 2 (A) PVD apparatus for preparation of Al thin film on gold (Au) surface and (B) preparation process of alumina-Az complex samples.

\subsection{Deposition of dyes onto the thin film}

In order to study the properties of the dye on an aluminum oxide film surface, 20 $\mathrm{uL}$ of $\mathrm{Az}$ aqueous solution $(0.5 \mathrm{~mol} / \mathrm{L})$ was dropped on the surface of the thin film prepared by PVD (see Fig. 2(B)). After 15 min, the excess of solvent was evaporated under Ar flux. To study the properties of the Dye- $\mathrm{Al}^{3+}$ complex on gold surface, a complex of $\mathrm{Az}-\mathrm{Al}^{3+}$ was prepared in water by mixing $\mathrm{Az}$ and $\mathrm{KAl}\left(\mathrm{SO}_{4}\right)_{2}$ with $\mathrm{Az} / \mathrm{Al}^{3+}$ ratios of $1: 1$ and $2: 1$. The $\mathrm{pH}$ was adjusted to 7.5 by addition of $\mathrm{KOH}$ solution. $20 \mathrm{uL}$ 
of $\mathrm{Az}-\mathrm{Al}^{3+}$ complex solution $(0.5 \mathrm{~mol} / \mathrm{L})$ was dropped on the surface of the thin film previously exposed to flame for three times. The excess of solvent was evaporated under Ar flux after 15-min deposition.

\subsection{Photostability}

The thin film was exposed to UV light. The distance from the light source and the film was $10 \mathrm{~cm}$. The UV light was the Lightningcure LC-L1V3 LED source from Hamamatsu Photonics with irradiance of $14000 \mathrm{~mW} / \mathrm{cm} 2$ at $365 \pm 5 \mathrm{~nm}$. The sample was characterized by PM-IRRAS after 0.5 h, 1 h, 2 h, 4 h, 7 h, 24 h, 33 h, 48 h, 76 h, $168 \mathrm{~h}$ and $264 \mathrm{~h}$.

\subsection{Characterization}

Attenuated total reflection Fourier transform infrared spectrum (ATR-FTIR) spectra were collected from a Cary 630 FTIR spectrometer in the range of 4000-650 $\mathrm{cm}^{-1}$.

CIE (Commission Internationale de L'Eclairage) parameters were obtained from an Ocean Optics spectrophotometer USB4000. The light source of Ocean Optics HL2000 was employed for CIE results. CIE 1976 color space system was applied to evaluate the color of the pigments. Lightness $\left(\mathrm{L}^{*}\right)$ represents the brightness $(+)$ or darkness $(-)$ of the color, i.e., more positive $L^{*}$ values refer to whiter while more negative $\mathrm{L}^{*}$ values represent darker. The values of $\mathrm{a}^{*}$ and $\mathrm{b}^{*}$ indicate the color details: $+a^{*}$ is the red direction, $-a^{*}$ the green direction, $+b^{*}$ the yellow direction, and $-b^{*}$ the blue direction. Before the reflectance and CIE tests, the samples were hand-pressed 
into pellets using $3 \mathrm{~mm}$ die set and a metal collar for Quick Press from Perkin Elmer (ref. 01862295) with the pressure about $10 \mathrm{MPa}$.

${ }^{13} \mathrm{C}$ and ${ }^{27} \mathrm{Al}$ magic angle spinning (MAS) nuclear magnetic resonance (NMR) spectra were obtained on a Bruker Advance III spectrometer equipped with a $2.5 \mathrm{~mm}$ and $4 \mathrm{~mm} \mathrm{H}-\mathrm{X}$ MAS probe, operating at frequency of $125.76 \mathrm{MHz}\left({ }^{13} \mathrm{C}\right)$ and 130.30 MHZ $\left({ }^{27} \mathrm{Al}\right)$. Chemical shifts were calibrated using the carboxyl signal of adamantane (38.52 ppm) for ${ }^{13} \mathrm{C}$ and $\mathrm{Al}\left(\mathrm{NO}_{3}\right)_{3}(0 \mathrm{ppm})$ for ${ }^{27} \mathrm{Al}$ as external standard. The ${ }^{13} \mathrm{C}$ cross-polarization (CP) spectra were acquired with a MAS rate of $14 \mathrm{kHz}$, a ramp-CP contact time of $2 \mathrm{~ms}$ and a $2 \mathrm{~s}$ of recycle delay and with a ${ }^{1} \mathrm{H}$ decoupling spinal. Over an acquisition time of $40 \mathrm{~ms}$, the number of scans to obtain the spectra depends on the signal to noise ratio obtained for each sample. Spectra were processed with a zero-filling factor of 2 and with an exponential decay corresponding to a $10 \mathrm{~Hz}$ line broadening in the transformed spectra. Only spectra with the same line broadening are directly compared. The ${ }^{27} \mathrm{Al}$ experiment using $30^{\circ}$ pulse was recorded in the same condition of spinning rate $(14 \mathrm{kHz})$, with a number of scans of $2048,263 \mathrm{kHz}$ spectral width and with $500 \mathrm{~ms}$ of recycle delay.

PM-IRRAS spectra were recorded using a Nicolet 5700 spectrometer equipped with a nitrogen-cooled MCT wide-band detector. The incident beam was modulated between $\mathrm{p}$ and $\mathrm{s}$ polarization using a $\mathrm{ZnSe}$ grid polarizer and $\mathrm{ZnSe}$ photoelastic modulator placed before the sample. The spectrometer was interfaced to the UHV chamber via $\mathrm{ZnSe}$ windows. The reflected light was focused onto the detector at an optimal incident angle of $85^{\circ}$. All spectra were obtained after 512 scans with a 
resolution of $8 \mathrm{~cm}^{-1}$.

3 Results and discussion

3.1 Influence of the Az concentration in lake pigments

\subsubsection{Chromatic analysis}

The CIE parameters (Table 1) of lakes pigments witness their colors. In the case of $\mathrm{R}=*$, the precipitation shows $\mathrm{L}^{*}, \mathrm{a}^{*}$ and $\mathrm{b}^{*}$ values of $99.7,0.2$ and -1.6 , respectively, indicating a white color for the substrate $\mathrm{Al}^{3+}-\mathrm{X}$ complex (Fig. 3). With the addition of Az, the CIE parameters of lake pigments changed. The lightness $\left(\mathrm{L}^{*}\right)$ of lake pigments decreased while the red $\left(+a^{*}\right)$ and blue $\left(+b^{*}\right)$ color components increased. Interestingly, the $a^{*}$ values of lake pigments are much larger than $b^{*}$ values, indicating that the lake pigments display red color (Fig. 3). The color of Az aqueous solution is readily affected by the $\mathrm{pH}$ value. In solid state, $\mathrm{Az}$ is yellow powder. However, the color of $\mathrm{Az}$ aqueous solution changes from yellow to red, and further to violet and blue with the increase of $\mathrm{pH}$ value. While, in the solid state, Az is a yellow powder, the color of Az aqueous solutions changes from yellow to red, and further to violet and blue, when increasing the $\mathrm{pH}$ value. In a basic solution, the chemical equilibrium of $\mathrm{Az}$ ionization was shifted to the right, generating more $\mathrm{Az}^{-}$and $\mathrm{Az}^{2-}$ anions, resulting in a red color. Hence, the $\mathrm{Al}^{3+}-\mathrm{Az}$ complex also displayed a red color. However, the real lake pigments were prepared with a very low concentration of $\mathrm{Az}$, suggesting that only a part of $\mathrm{Al}^{3+}$ cations were coordinated with $\mathrm{Az}$ and others were still under the $\mathrm{AlO}(\mathrm{OH})$ complex form. With the increase of $\mathrm{Az}$ concentration, the $\mathrm{L}^{*}$ 
value of lake pigments increased while the $a^{*}$ and $b^{*}$ values were almost stable. Hence, the concentration of Az influenced the color nature of these lake pigments by changing their lightness. Less Az resulted in a brighter color.

Table 1 CIE parameters of lake pigments prepared with Az.

\begin{tabular}{llll}
\hline $\mathrm{R}$ & $\mathrm{L}^{*}$ & $\mathrm{a}^{*}$ & $\mathrm{~b}^{*}$ \\
\hline$*$ & 99.7 & 0.2 & -1.6 \\
5 & 33.9 & 43.6 & 8.5 \\
25 & 39.5 & 43.5 & 10.9 \\
50 & 45.6 & 45.6 & 10.5 \\
100 & 53.9 & 41.5 & 8.7 \\
200 & 61.6 & 40.6 & 7.8 \\
\hline
\end{tabular}

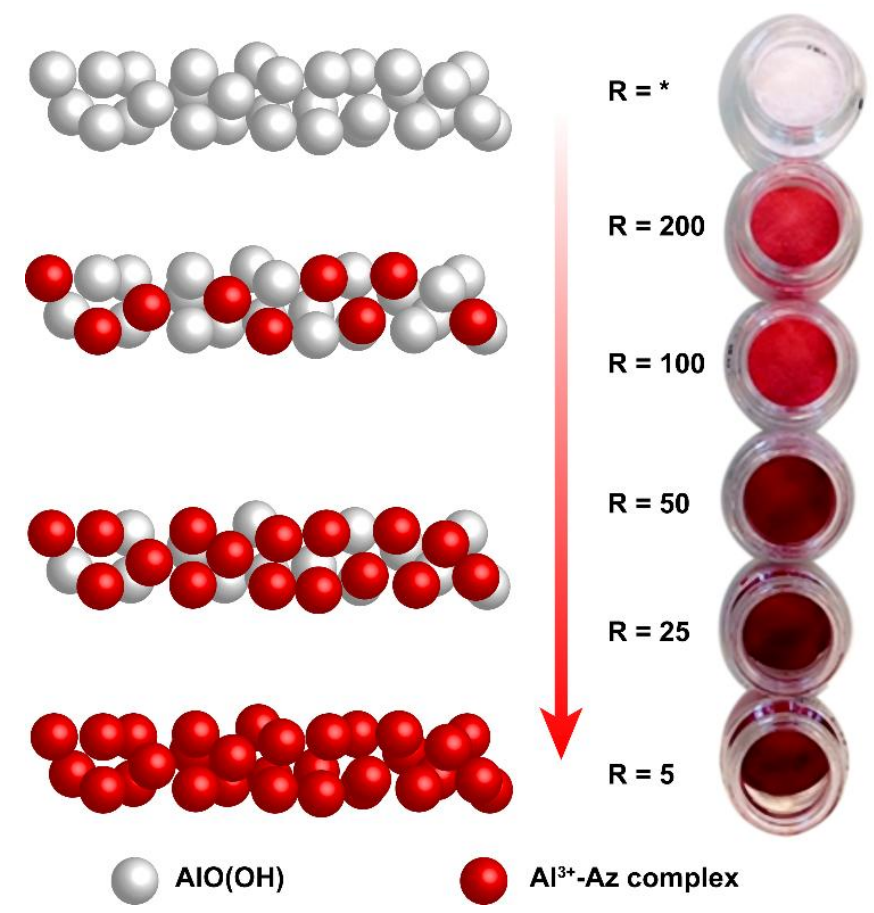

Fig. 3 Digital pictures of lake pigments and corresponding interpretive diagrams. 


\subsubsection{ATR-FTIR}

The FTIR spectrum of $\mathrm{Az}$ is presented in Fig. 4. In agreement with previous reports $[4,42,43]$, the assignments are summarized in Table 2 . The absorption band at $3359 \mathrm{~cm}^{-1}$ belongs to the vibration of phenolic hydroxyl groups. The characteristic bands are $v(\mathrm{C}=\mathrm{O})$ at $1661 \mathrm{~cm}^{-1}(\mathrm{C} 10)$ and $v(\mathrm{C}=\mathrm{O})$ at $1631 \mathrm{~cm}^{-1}(\mathrm{C} 9) ; v(\mathrm{C}=\mathrm{C})$ of benzene ring at 1584 and $1449 \mathrm{~cm}^{-1}$, in addition to out of plan deformation bands at 1194, 1179 and $1158 \mathrm{~cm}^{-1}$, and group bands at 1047, 1031, $\left.1012 \mathrm{~cm}^{-1}\right) ; \delta(\mathrm{O}-\mathrm{H})$ at $1349 \mathrm{~cm}^{-1}(\mathrm{C} 2)$ and $1329 \mathrm{~cm}^{-1}(\mathrm{C} 1) ; \mathrm{v}(\mathrm{C}-\mathrm{O})$ at $1280 \mathrm{~cm}^{-1}(\mathrm{C} 2)$ and $1263 \mathrm{~cm}^{-1}(\mathrm{C} 1)$.

In the case of $\mathrm{R}=*$ (without the addition of $\mathrm{Az}$ ), four bands are observed in the FTIR spectrum. A wide band $\left(3000-3750 \mathrm{~cm}^{-1}\right)$ centered at $3414 \mathrm{~cm}^{-1}$ is attributed to the stretching vibration of $\mathrm{O}-\mathrm{H}$ from coordinated hydroxyl group $(\mathrm{Al}-\mathrm{OH})$ and water, corresponding to the bending vibration at $1104 \mathrm{~cm}^{-1}(\delta(\mathrm{Al}-\mathrm{OH}))$ and 1638 $\mathrm{cm}^{-1}\left(\delta\left(\mathrm{H}_{2} \mathrm{O}\right)\right)$, respectively[44-46]. This result demonstrated that both $-\mathrm{OH}$ and $\mathrm{H}_{2} \mathrm{O}$ coordinated with $\mathrm{Al}^{3+}$. Furthermore, the signals of $v(\mathrm{Al}-\mathrm{O}-\mathrm{Al})$ at $978 \mathrm{~cm}^{-1}$ and $v(\mathrm{Al}-\mathrm{O})$ at $852 \mathrm{~cm}^{-1}$ are observed, indicating the formation of a polymetric $\mathrm{Al}^{3+}$ complex. The lake pigment substrate is loosely described as hydrated alumina, but in practice is difficult to characterize, partly because it is amorphous and highly variable state [47]. It does not correspond to any of the various crystalline aluminum (oxy)hydroxides or anhydrous oxides, many of which are known mineral species such as gibbsite $\mathrm{Al}(\mathrm{OH})_{3}$ or boehmite $(\gamma-\mathrm{AlOOH})[48-52]$. The bands at 1508 and 1417 $\mathrm{cm}^{-1}$ are assigned to the stretching vibration of $\mathrm{CO}_{3}{ }^{2-}$ group, implying that carbonates were included in the substrate. 
When Az was added ( $\mathrm{R}$ in the range 5 to 200), the FTIR spectra of samples present some shifts in comparison with that of Az. Firstly, the absorption bands referring to Az show lower intensity with the increase of $\mathrm{R}$ values. This phenomenon not only demonstrates the immobilization of $\mathrm{Az}$ molecules in the precipitation, but also testifies that smaller $\mathrm{R}$ value results in more Az included in the lakes. Secondly, compared with the FTIR spectrum of $\mathrm{Az}$, the bands referring to $\mathrm{C}=\mathrm{C}, \mathrm{C}=\mathrm{O}$, and $\mathrm{C}-\mathrm{O}$ and $\mathrm{O}-\mathrm{H}$ groups shifted to higher or lower wavenumbers in the lake spectra. The two bands referring to the two $\mathrm{C}=\mathrm{O}$ groups merged at $1638 \mathrm{~cm}^{-1}$. The $v(\mathrm{C}=\mathrm{C})$ band from benzene ring splits into four bands at 1590, 1519, 1469 and $1435 \mathrm{~cm}^{-1}$. The bands referring to $\delta(\mathrm{O}-\mathrm{H})$ shifted to 1355 and $1321 \mathrm{~cm}^{-1}$ from 1349 and $1329 \mathrm{~cm}^{-1}$. The $\mathrm{C} 2$ $v(\mathrm{C}-\mathrm{O})$ signal shifted to 1287 from $1280 \mathrm{~cm}^{-1}$. This fact indicates the interaction between $\mathrm{Az}$ and $\mathrm{Al}^{3+}$. The bands representing the vibrations of $\delta(\mathrm{Al}-\mathrm{OH})$ at 1104 $\mathrm{cm}^{-1}, v(\mathrm{Al}-\mathrm{O}-\mathrm{Al})$ at $978 \mathrm{~cm}^{-1}$ and $v(\mathrm{Al}-\mathrm{O}) 852 \mathrm{~cm}^{-1}$ remained in the ATR-FTIR spectra of Az lakes, demonstrating no changes happened to the substrate. But these bands exhibited lower intensity with the increase of $\mathrm{R}$ value, because of the low concentration of $\mathrm{Al}^{3+}$ (high concentration of $\mathrm{Az}$ ). Particularly, the lake pigments with $\mathrm{R}=50$ and 200 showed the remarkable signal of $\mathrm{Al}-\mathrm{OH}$ group. This fact demonstrates that less $\mathrm{Az}$ molecules results in more $\mathrm{Al}-\mathrm{OH}$ groups. The $\mathrm{Az}$ competed with $-\mathrm{OH}$ for coordinating with $\mathrm{Al}^{3+}$. 


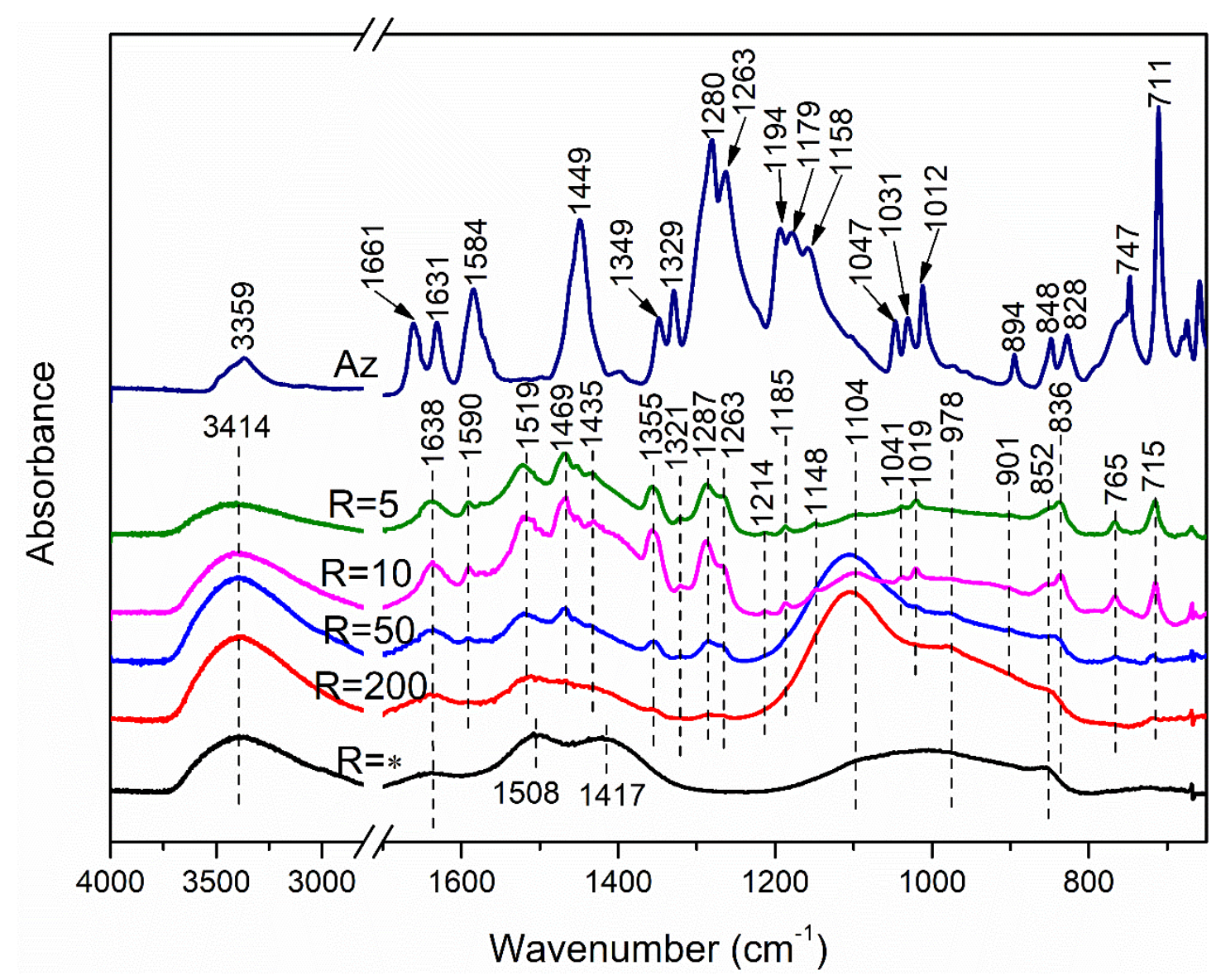

Fig. 4 ATR-FTIR spectra of Az and lakes with different $R$ values.

Table 2 The assignments of FTIR bands of Az and the corresponding shifts in lakes.

Absorption band $\left(\mathrm{cm}^{-1}\right)$

Assignment

$\mathrm{Az} \quad$ Lake pigment

3359

$v(\mathrm{O}-\mathrm{H})$

1661

$v(\mathrm{C}=\mathrm{O}) \mathrm{C} 10$

1638

$v(\mathrm{C}=\mathrm{O}) \mathrm{C} 9 / \delta(\mathrm{O}-\mathrm{H})$ water

1631

$v(\mathrm{C}=\mathrm{O}) \mathrm{C} 9$

1584

1590

$v(\mathrm{C}=\mathrm{C})$

1519

$v(\mathrm{C}=\mathrm{C})$ 


\begin{tabular}{|c|c|c|}
\hline & 1469 & $v(\mathrm{C}=\mathrm{C})$ \\
\hline 1449 & 1435 & $v(\mathrm{C}=\mathrm{C})$ \\
\hline 1349 & 1355 & $\delta(\mathrm{O}-\mathrm{H})$ phenol C2 \\
\hline 1329 & 1321 & $\delta(\mathrm{O}-\mathrm{H})$ phenol C1 \\
\hline 1280 & 1287 & $v(\mathrm{C}-\mathrm{O}) \mathrm{C} 2$ \\
\hline 1263 & 1263 & $v(\mathrm{C}-\mathrm{O}) \mathrm{C} 1$ \\
\hline \multirow[t]{2}{*}{$1194 / 1179 / 1158$} & $1185 / 1148$ & $v(\mathrm{C}=\mathrm{C}) / \delta(\mathrm{CCC}) / \delta(\mathrm{C}-\mathrm{H})$ \\
\hline & 1104 & $\delta(\mathrm{Al}-\mathrm{OH})$ \\
\hline $1047 / 1031 / 1012$ & 1019 & $v(\mathrm{C}=\mathrm{C}) / \delta(\mathrm{CCC}) / \delta(\mathrm{C}-\mathrm{H})$ \\
\hline \multirow[t]{3}{*}{$894 / 848 / 827$} & & $\gamma(\mathrm{C}-\mathrm{H}) / \delta(\mathrm{C}=\mathrm{O}) / \gamma(\mathrm{C}=\mathrm{C}) / \delta(\mathrm{CCC}) / \gamma(\mathrm{C}-\mathrm{H})$ \\
\hline & 978 & $v(\mathrm{Al}-\mathrm{O}-\mathrm{Al})$ \\
\hline & 852 & $v(\mathrm{Al}-\mathrm{O})$ \\
\hline 748 & 766 & $\delta(\mathrm{CCC})$ \\
\hline 712 & 715 & $\gamma(\mathrm{C}-\mathrm{O}) / \gamma(\mathrm{C}=\mathrm{O})$ \\
\hline
\end{tabular}

Note: $v$-stretching vibration, $\delta$-bending in-plane, $\gamma$-bending out-of-plane.

\subsubsection{NMR}

The ${ }^{27} \mathrm{Al}$ MAS NMR spectra of Az lake pigments (Fig. 5 (A)) reveal the coordination nature of $\mathrm{Al}^{3+}$ in $\mathrm{Az}$ lakes. Three signals are observed in the spectrum of precipitation without $\mathrm{Az}(\mathrm{R}=*)$, i.e., $\mathrm{Al}(\mathrm{VI})$ (hexa-coordinated $\left.\mathrm{Al}^{3+}\right)$ at $7.1 \mathrm{ppm}, \mathrm{Al}(\mathrm{V})$ (penta-coordinated $\mathrm{Al}^{3+}$ ) at $36.1 \mathrm{ppm}$ and $\mathrm{Al}(\mathrm{IV})$ (tetra-coordinated $\mathrm{Al}^{3+}$ ) at $66.7 \mathrm{ppm}$ [53]. Comparing the area of NMR signals by integration, $89 \%$ of $\mathrm{Al}(\mathrm{VI}), 7 \%$ of $\mathrm{Al}(\mathrm{V})$ 
and $4 \%$ of $\mathrm{Al}(\mathrm{IV})$ were included in the substrate. Previous work also proved the presence of $\mathrm{Al}(\mathrm{VI})$ in the lakes. However, the authors ignored the minor presence of $\mathrm{Al}(\mathrm{V})$ and $\mathrm{Al}(\mathrm{IV})$ in spite of the ${ }^{27} \mathrm{Al}$ NMR spectra indicating weak signals. The most $\mathrm{Al}(\mathrm{VI})$ demonstrated major octahedral $\left[\mathrm{AlO}_{6}\right]$ structure in the framework of inorganic substrate, indicating a polymetric complex. On the other hand, the presence of $\mathrm{Al}(\mathrm{V})$ and Al(IV) suggested some defects in the complex structure. The lake pigments $\left(\mathrm{R}=25\right.$ and 50) displayed similar ${ }^{27} \mathrm{Al}$ MAS NMR spectra with the precipitation without $\mathrm{Az}$, demonstrating the similar coordination environment of $\mathrm{Al}^{3+}$ in the lake pigments. Most of $\mathrm{Al}^{3+}$ cations are coordinated with $6 \mathrm{O}$ atoms, but some are coordinated with 5 or $4 \mathrm{O}$ atoms. Thus, the introduction of $\mathrm{Az}$ did not influence the coordination structure of $\mathrm{Al}^{3+}$ complex.
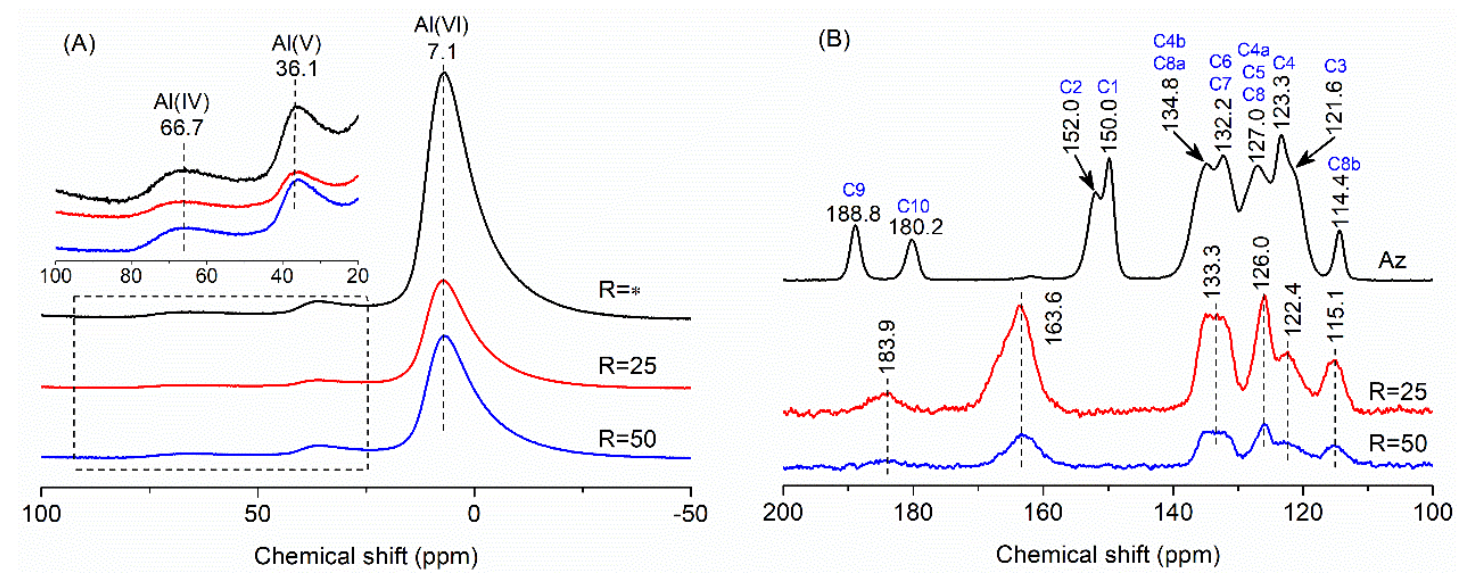

Fig. 5 (A) ${ }^{27} \mathrm{Al}$ and (B) ${ }^{13} \mathrm{C}$ MAS NMR spectra of Az lake pigments.

The ${ }^{13} \mathrm{C}$ MAS NMR spectra of $\mathrm{Az}$ and lake pigments are presented in Fig. 5 (B). The chemical shifts of $\mathrm{C} 1$ is smaller than that of $\mathrm{C} 2$, due to the hydrogen bond (Fig. 1). Accordingly, $C 9$ shows higher chemical shift than $\mathrm{C} 10$, because the intramolecular hydrogen bonds decrease the electron density of C9 by delocalization. Compared with 
$\mathrm{Az}$, the NMR spectra of lake pigments exhibit some shifts. The chemical shifts of Az remained in the lake pigments, except for the signals of $\mathrm{C} 1, \mathrm{C} 2, \mathrm{C} 9$ and $\mathrm{C} 10$. Both chemical shifts of $\mathrm{C} 1$ and $\mathrm{C} 2$ increased to $163.6 \mathrm{ppm}$ from 150.0 and $152.0 \mathrm{ppm}$, implying that the electron density of $\mathrm{C} 1$ and $\mathrm{C} 2$ decreased when $\mathrm{Az}$ interacted with $\mathrm{Al}^{3+}$. C9 and C10 signals shifted to $183.9 \mathrm{ppm}$ in lake pigments. This suggested the conjugative effect, which averaged the electron distribution in $\mathrm{Az}$ molecules coordinated with $\mathrm{Al}^{3+}$.

Az has two phenolic hydroxyl groups, which can release protons (Fig. 1). Two acid-basic equilibria happen when Az is in aqueous solution. Kuban and Havel (1973) [39] reported the $\mathrm{pK}_{\mathrm{a} 1}=5.25$ and $\mathrm{pK}_{\mathrm{a} 2}=11.50$ of Az. Later, Miliani et al. (2000) [9] reported the $\mathrm{pK}_{\mathrm{a} 1}$ and $\mathrm{pK}_{\mathrm{a} 2}$ values as 6.57 and 12.36, respectively. Hence, $\mathrm{pH}$ value directly influences the proportion of $\mathrm{Az}, \mathrm{Az}^{-}, \mathrm{Az}^{2-}$ and $\mathrm{H}^{+}$. Besides, two $\mathrm{C}=\mathrm{O}$ groups are also included in an $\mathrm{Az}$ molecule. Thus, $\mathrm{Az}$ can be considered as a bidentate ligand[4, 32-35, 54, 55]. For metal ion fixation, Az presents two potential sites in competition: the 1,2-dihydroxyl (catechol) and the 1-hydroxy-9-keto groups[34]. If a monodentate fixation mode could be considered, bidentate complexes are usually the most stable ones, for such ligands. Two contradictory hypothesis are proposed in the literature, an $\mathrm{Al}^{3+}$ fixation with the catechol group $[55,56]$ and a metal chelation with the 1-hydroxy-9-keto group [4, 28, 31]. Both chemical shifts of $\mathrm{C} 1$ and $\mathrm{C} 2$ increased from 150.0 and $152.0 \mathrm{ppm}$ to $163.6 \mathrm{ppm}$ while the chemical shifts of C9 (188.8 ppm) and $\mathrm{C} 10$ (180.2 ppm) equalized to $183.9 \mathrm{ppm}$. This fact demonstrates that $\mathrm{Al}^{3+}$ cations are fixed with the catechol groups in Az molecules, instead of 1-hydroxy-9-keto 
groups. This result is in accordance with a recent report[34]

There are 6 possible coordinated structures of $\mathrm{Al}^{3+}-\mathrm{Az}^{2-}$ complexes (Fig. 6). $\mathrm{Al}^{3+}$ cations coordinated with $\mathrm{O}$ atoms from $\mathrm{H}_{2} \mathrm{O}$ or $\mathrm{OH}^{-}$, i.e., [ $\mathrm{AlX}_{6}$ ], [ $\mathrm{AlX}_{5}$ ] and [ $\left.\mathrm{AlX}_{4}\right]$ (X refers to $\mathrm{H}_{2} \mathrm{O}$ or $\mathrm{OH}^{-}$). The structures of lake pigments can be described as the replacement of $\mathrm{Al}-\mathrm{X}$ complexes by some $\mathrm{Az}^{2-}$ anions. $\mathrm{C}-\mathrm{O}^{-}(\mathrm{C} 1$ and $\mathrm{C} 2)$ groups donated the electrons to the unoccupied orbitals of $\mathrm{Al}^{3+}$, resulting in the chemical shift of $\mathrm{C} 1$ and $\mathrm{C} 2$ to higher values. In $\mathrm{Al}^{3+}-\mathrm{Az}^{2-}$ complexes, the distribution of electrons became delocalized due to the coordination with $\mathrm{Al}^{3+}$, resulting in the identical chemical shift of $\mathrm{C} 1$ and $\mathrm{C} 2$, as well as $\mathrm{C} 9$ and $\mathrm{C} 10$.

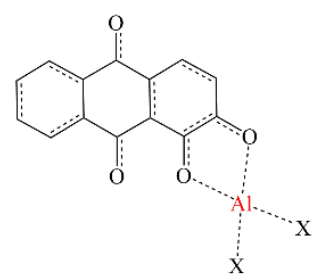

(A)

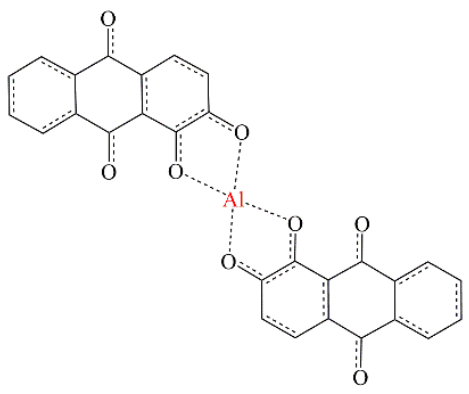

(D)

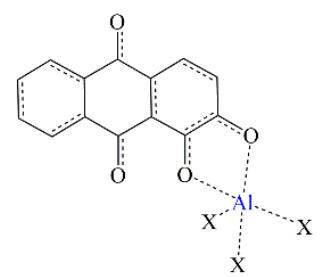

(B)

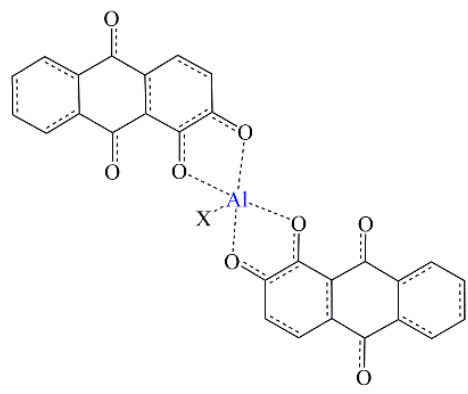

(E)

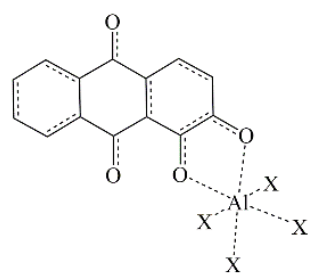

(C)

$$
\text { Symbol } \quad \mathrm{Al}: \mathrm{Al}(\mathrm{IV}) \quad \mathrm{Al}: \mathrm{Al}(\mathrm{V}) \quad \mathrm{Al}: \mathrm{Al}(\mathrm{VI}) \quad \mathrm{X}: \mathrm{H}_{2} \mathrm{O} \text { or } \mathrm{OH} \text { coordinated to } \mathrm{Al}^{3+}
$$

Fig. 6 The possible coordinated structures of $\mathrm{Az}^{-\mathrm{Al}^{3+}}$ complexes: (A) $\mathrm{Al}\left[\mathrm{AzX} \mathrm{X}_{2}\right]$, (B) $\mathrm{Al}\left[\mathrm{AzX}_{3}\right],(\mathrm{C}) \mathrm{Al}\left[\mathrm{AzX}_{4}\right],(\mathrm{D}) \mathrm{Al}\left[(\mathrm{Az})_{2}\right],(\mathrm{E}) \mathrm{Al}\left[(\mathrm{Az})_{2} \mathrm{X}\right]$ and (F) $\mathrm{Al}\left[(\mathrm{Az})_{2} \mathrm{X}_{2}\right]$. 


\subsubsection{Chromatic analysis}

The CIE parameters of lake pigments prepared with $\mathrm{K}_{2} \mathrm{CO}_{3}$ and $\mathrm{KOH}$ are listed in Table 3. At the same $\mathrm{pH}$ value, the lake pigments prepared with $\mathrm{K}_{2} \mathrm{CO}_{3}$ showed lower $\mathrm{L}^{*}$ and $\mathrm{b}^{*}$ values, but larger $\mathrm{a}^{*}$ value than those of lake pigments prepared with $\mathrm{KOH}$. Hence, $\mathrm{K}_{2} \mathrm{CO}_{3}$ resulted in redder but less bright color than $\mathrm{KOH}$. The $\mathrm{pH}$ value also affected the color of lake pigments. With the increase of $\mathrm{pH}$ value, the $\mathrm{L}^{*}$ decreased while the $a^{*}$ and $b^{*}$ value increased, suggesting that the increase of $\mathrm{pH}$ value leads to a lower brightness and blue color. The bases and $\mathrm{pH}$ value influenced the color of lake pigments, with minor differences between $\mathrm{K}_{2} \mathrm{CO}_{3}$-lakes and $\mathrm{KOH}$-lakes (Fig. 7).

Table 3 Influence of basic reagents on the CIE parameters of Az pigments prepared at different $\mathrm{pH}$ values.

\begin{tabular}{lllllll}
\hline & \multicolumn{5}{c}{$\mathrm{L}^{*}$} & \multicolumn{3}{c}{$\mathrm{a}^{*}$} & \multicolumn{3}{c}{$\mathrm{b}^{*}$} \\
\cline { 2 - 6 } $\mathrm{pH}$ & $\mathrm{K}_{2} \mathrm{CO}_{3}$ & $\mathrm{KOH}$ & $\mathrm{K}_{2} \mathrm{CO}_{3}$ & $\mathrm{KOH}$ & $\mathrm{K}_{2} \mathrm{CO}_{3}$ & $\mathrm{KOH}$ \\
\hline 5.5 & 51.2 & 55.7 & 41.8 & 41.8 & 7.0 & 10.9 \\
6.5 & 44.7 & 53.1 & 47.5 & 45.1 & 9.4 & 15.8 \\
7.5 & 44.9 & 56.4 & 47.0 & 39.7 & 8.5 & 10.7 \\
8.5 & 45.4 & 47.5 & 48.4 & 43.3 & 9.3 & 12.9 \\
\hline
\end{tabular}




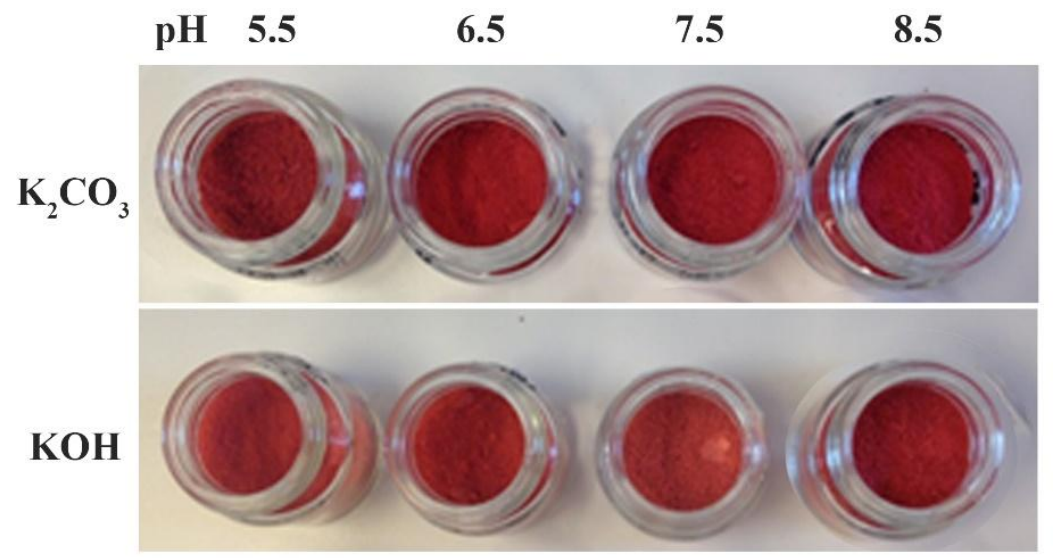

Fig. 7 Digital pictures of lake pigments.

\subsubsection{ATR-FTIR}

The precipitation of $\mathrm{Al}^{3+}$ is not only resulting from carbonate $\left(\mathrm{K}_{2} \mathrm{CO}_{3}\right)$ but also from alkali (e.g. $\mathrm{KOH})$. The ATR-FTIR spectra of lake pigments prepared with $\mathrm{K}_{2} \mathrm{CO}_{3}$ and $\mathrm{KOH}$ are given in Fig. 8. In Fig. 8(A), the band at $3396 \mathrm{~cm}^{-1}$ refers to the stretching vibration of coordinated $\mathrm{H}_{2} \mathrm{O}$, whose bending vibration appeared at 1639 $\mathrm{cm}^{-1}$. In addition, the $v(\mathrm{Al}-\mathrm{OH})$ signal was overlapped by the wide band at 3396 $\mathrm{cm}^{-1}$, corresponding to the $\delta(\mathrm{Al}-\mathrm{OH})$ at $1103 \mathrm{~cm}^{-1}$. The band at $1103 \mathrm{~cm}^{-1}$ is assigned to the bending vibration (in-plane) of $\mathrm{Al}-\mathrm{OH}$ group, the band at $974 \mathrm{~cm}^{-1}$ is attributed to $\mathrm{Al}-\mathrm{O}-\mathrm{Al}$ group, and the band at $854 \mathrm{~cm}^{-1}$ belongs to $\mathrm{Al}-\mathrm{O}$ groups. In addition, the bands at 1499 and $1430 \mathrm{~cm}^{-1}$ are assigned to $\mathrm{CO}_{3}{ }^{2-}$ groups coordinated to $\mathrm{Al}^{3+}$. Carbonates are absent in the precipitation prepared at $\mathrm{pH}=5.5$ while they present at $\mathrm{pH}$ value above 6.5. This demonstrated that carbonates were included in the precipitations when using $\mathrm{K}_{2} \mathrm{CO}_{3}$ as the base reagent. However, carbonates can only be present at $\mathrm{pH}>6.5$, because they are instable in acidic condition. The precipitation at $\mathrm{pH}=5.5$ showed a great signal at $1103 \mathrm{~cm}^{-1}(\mathrm{Al}-\mathrm{OH})$ and $974 \mathrm{~cm}^{-1}(\mathrm{Al}-\mathrm{O}-\mathrm{Al})$, 
while the band at $850 \mathrm{~cm}^{-1}(\mathrm{Al}-\mathrm{O})$ was very weak. With the increase of $\mathrm{pH}$ value, the intensities of $\mathrm{Al}-\mathrm{OH}$ and $\mathrm{Al}-\mathrm{O}-\mathrm{Al}$ groups decreased dramatically while the signal of $\mathrm{Al}-\mathrm{O}$ group increased. This phenomenon implied that polymeric $\mathrm{Al}^{3+}-\mathrm{X}$ complexes formed at a low $\mathrm{pH}$ value, e.g., $\mathrm{pH}=5.5$, while individual chelates tended to be synthesized at $\mathrm{pH}$ above 6.5 .

Compared with the FTIR spectra of precipitates prepared with $\mathrm{K}_{2} \mathrm{CO}_{3}$, those of precipitates prepared with $\mathrm{KOH}$ (Fig. 8(B)) did not display the signals of carbonates. The bands of coordinated water and $-\mathrm{OH}$ group emerged at 3370 and $1640 \mathrm{~cm}^{-1}$. The bands at 1093 and $1054 \mathrm{~cm}^{-1}$ are assigned to the symmetric and asymmetric bending vibration of $\mathrm{Al}-\mathrm{OH}$ group. The signal at $976 \mathrm{~cm}^{-1}$ belongs to the stretching vibration of $\mathrm{Al}-\mathrm{O}-\mathrm{Al}$ group. The stretching vibration of $\mathrm{Al}-\mathrm{O}$ group occurred at $880 \mathrm{~cm}^{-1}$. With the increase of $\mathrm{pH}$ value, the intensity of absorption at 3370 and $1640 \mathrm{~cm}^{-1}$ decreased, as well as the signal of $\mathrm{Al}-\mathrm{OH}$ group, suggesting the loss of $-\mathrm{OH}$ groups coordinated with $\mathrm{Al}^{3+}$ and/or coordinated water. In addition, the precipitations prepared with $\mathrm{KOH}$ showed stronger signal of $v(\mathrm{Al}-\mathrm{O}-\mathrm{Al})$ than those precipitations prepared with $\mathrm{K}_{2} \mathrm{CO}_{3}$, suggesting more $-\mathrm{OH}$ groups coordinated with $\mathrm{Al}^{3+}$ in the presence of $\mathrm{KOH}$.

The lake pigments prepared with $\mathrm{K}_{2} \mathrm{CO}_{3}$ showed complex FTIR spectra of Az and precipitates (Fig. 8(C)). Except for the bands of substrate, the signals of Az were observed. The stretching vibration of $\mathrm{C}=\mathrm{O}$ was overlapped at $1633 \mathrm{~cm}^{-1}$. The stretching vibrations of benzene ring appeared at 1590, 1518 and $1469 \mathrm{~cm}^{-1}$. The bending vibration of phenol $-\mathrm{OH}$ group appeared at $1354 \mathrm{~cm}^{-1}$. The wide band 
between 1261 and $1285 \mathrm{~cm}^{-1}$ are assigned to the stretching vibrations of $\mathrm{C} 1$ and $\mathrm{C} 2$ $\mathrm{C}=\mathrm{O}$ groups. The broad band between 1400 and $1500 \mathrm{~cm}^{-1}$ is assigned to the stretching vibration of $\mathrm{CO}_{3}{ }^{2-}$ groups. Compared with the FTIR spectrum of Az, the lake pigments prepared with $\mathrm{K}_{2} \mathrm{CO}_{3}$ exhibited some shifts: (i) The bands referring to two $v(\mathrm{C}=\mathrm{O})$ vibrations at $1661 \mathrm{~cm}^{-1}(10-\mathrm{C}=\mathrm{O})$ and $1638 \mathrm{~cm}^{-1}(9-\mathrm{C}=\mathrm{O})$ merged and shifted to $1633 \mathrm{~cm}^{-1}$; (ii) The benzene ring $v(\mathrm{C}=\mathrm{C})$ at 1584 and $1449 \mathrm{~cm}^{-1}$ split and shifted to 1590,1518 and $1469 \mathrm{~cm}^{-1}$; (iii) The $\delta(\mathrm{O}-\mathrm{H})$ at $1349 / 1329 \mathrm{~cm}^{-1}$ shifted to $1354 \mathrm{~cm}^{-1}$, and the $v(\mathrm{C}=\mathrm{O})$ at 1281 and $1263 \mathrm{~cm}^{-1}$ merged into a broad band. These changes demonstrated the conjugative effect which averaged the electron distribution of $\mathrm{Al}^{3+}-\mathrm{Az}$ complex. Particularly, we also noticed the wide band between 1400 and $1500 \mathrm{~cm}^{-1}$ assigned to $\mathrm{CO}_{3}{ }^{2-}$ groups. The FTIR spectra of lake pigments prepared with $\mathrm{KOH}$ (Fig. 8(D)) are similar to those of lakes prepared with $\mathrm{K}_{2} \mathrm{CO}_{3}$, except for the absence of the wide bands of $\mathrm{CO}_{3}{ }^{2-}$. The key difference between the lake pigments prepared with $\mathrm{K}_{2} \mathrm{CO}_{3}$ and $\mathrm{KOH}$ lies in the coordinated -OH groups (1000-1200 $\mathrm{cm}^{-1}$ ). With the increase of $\mathrm{pH}$ value, $\mathrm{Az}$ lakes prepared with $\mathrm{KOH}$ showed higher absorption than those prepared with $\mathrm{K}_{2} \mathrm{CO}_{3}$, demonstrating more $-\mathrm{OH}$ groups included in the complexes. 

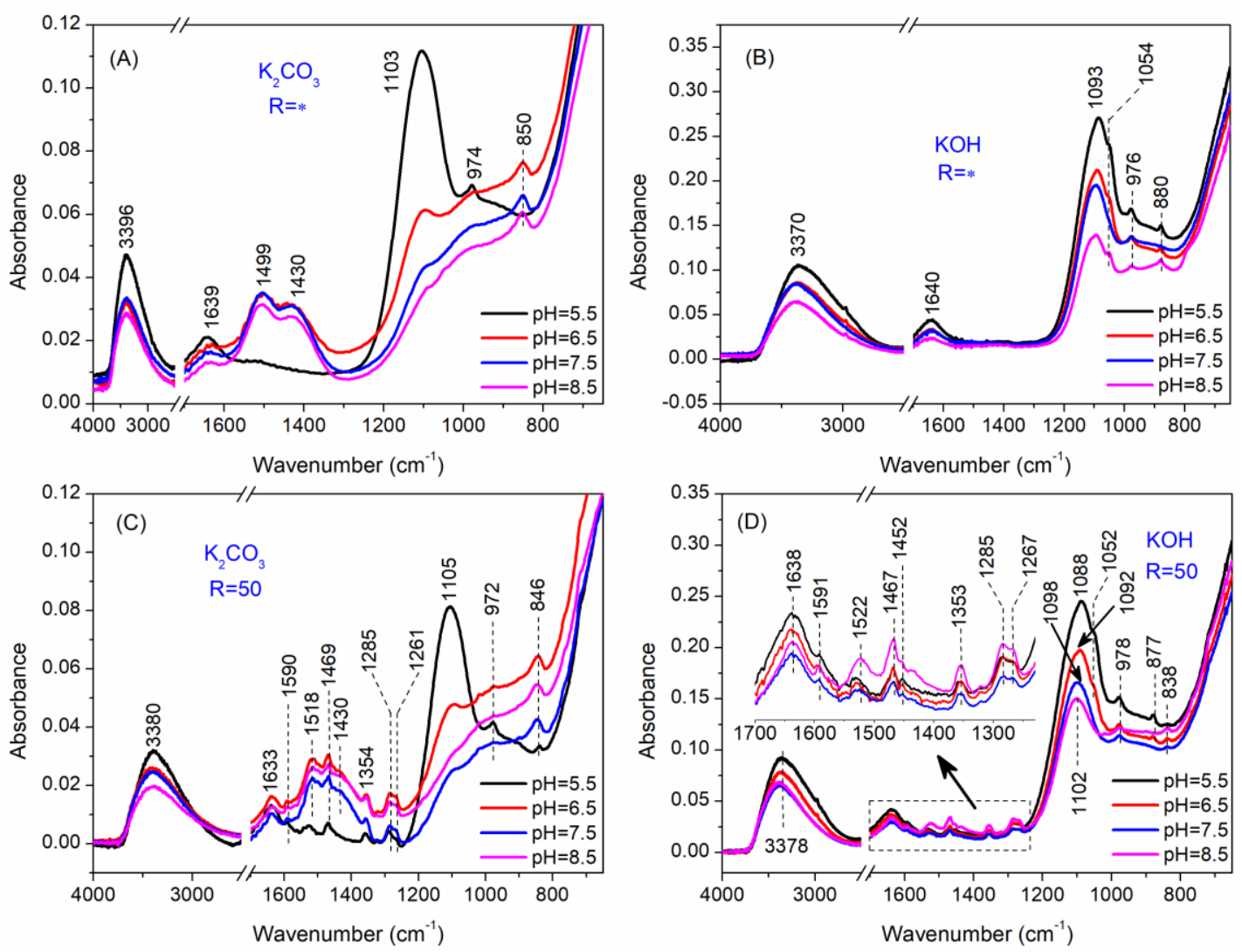

Fig. 8 ATR-FTIR spectra of lake pigments prepared with different bases.

3.3 Interaction between $\mathrm{Al}_{2} \mathrm{O}_{\mathrm{X}}$ film and dyes

The PM-IRRAS spectra of $\mathrm{Al}^{3+}-\mathrm{Az}$ complexes on Au film (Fig. 9 (A)) indicate the interaction between $\mathrm{Al}^{3+}-\mathrm{Az}$ complex and $\mathrm{Au}$ film. The $\mathrm{Al}^{3+}-\mathrm{Az}$ complexes $\left(\mathrm{Al}^{3+} / \mathrm{Az}=\right.$ 1:1 and 1:2) on $\mathrm{Au}$ films, i.e., $\mathrm{Au}-\mathrm{Al}^{3+}{ }_{1} / \mathrm{Az}_{1}$ and $\mathrm{Au}-\mathrm{Al}^{3+}{ }_{1} / \mathrm{Az}_{2}$, show characteristic bands of $\mathrm{Al}^{3+}-\mathrm{Az}$ complex. The band at $1643 \mathrm{~cm}^{-1}$ can be attributed to the $v(\mathrm{C}=\mathrm{O})$ of $\mathrm{Az}$ and to the $\delta(-\mathrm{OH})$ of coordinated water. The $v(\mathrm{C}=\mathrm{C})$ vibration of benzene ring emerged at 1593,1531 and $1471 \mathrm{~cm}^{-1}$. The band at $1361 \mathrm{~cm}^{-1}$ belongs to $\delta(-\mathrm{OH})$ from phenol group. The absorptions at 1291 and $1268 \mathrm{~cm}^{-1}$ are assigned to the $v(\mathrm{C}-\mathrm{O}) . \mathrm{Az}$ deposited on $\mathrm{Au}-\mathrm{Al}_{2} \mathrm{O}_{\mathrm{x}}$ film (Fig. 9(B)) also exhibit similar PM-IRRAS spectrum with $\mathrm{Al}^{3+}-\mathrm{Az}$ complexes on $\mathrm{Au}$ film. This phenomenon demonstrates that $\mathrm{Az}$ molecules 
interacted with $\mathrm{Al}_{2} \mathrm{O}_{\mathrm{x}}$ film surface very similarly to $\mathrm{Al}^{3+}$-Az complexes. The band at $945 \mathrm{~cm}^{-1}$ is assigned to the stretching vibration of $\mathrm{Al}-\mathrm{O}-\mathrm{Al}$ groups, which belong to the $\mathrm{Al}_{2} \mathrm{O}_{\mathrm{x}}$ substrate. This band in Fig. 9 (A) is absent due to Au substrate, instead of $\mathrm{Al}_{2} \mathrm{O}_{\mathrm{x}}$. But this phenomenon suggests that the deposition of $\mathrm{Al}^{3+}-\mathrm{Az}$ complex did not form a polymetric structure like the bulk lakes, maybe because of the small amount (only on the surface and remove excess complex after $15 \mathrm{~min}$ ).
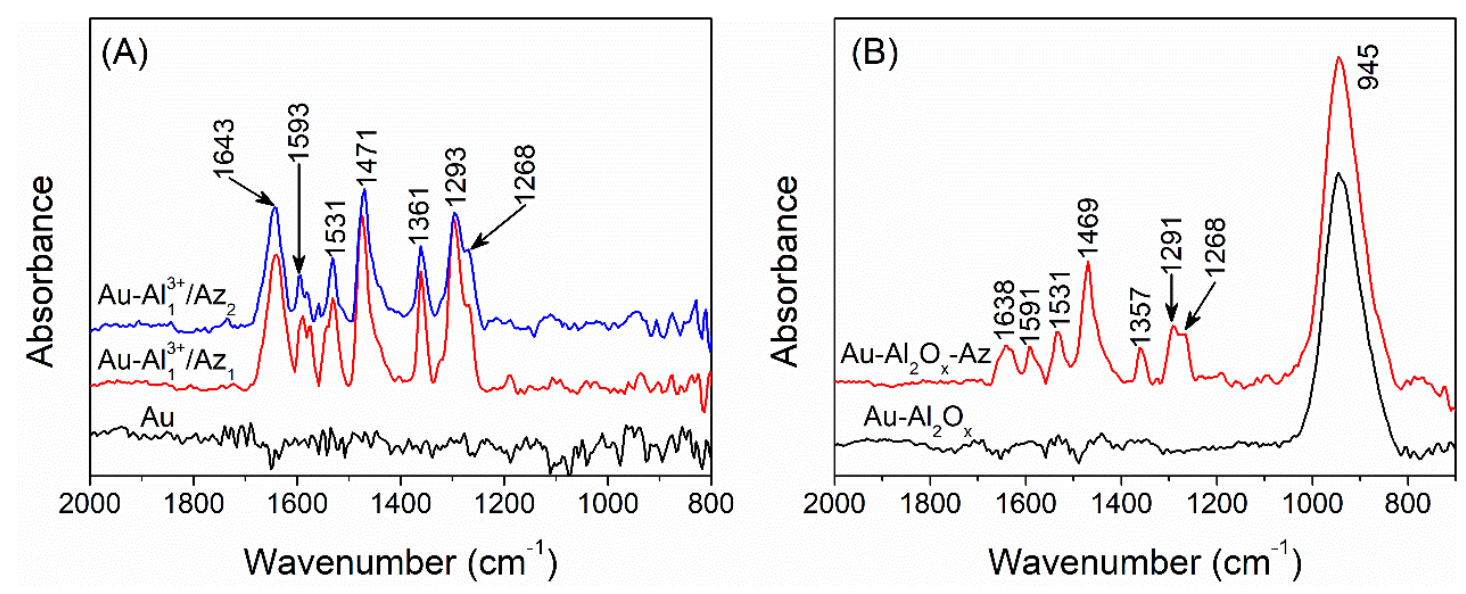

Fig. 9 PM-IRRAS spectra of (A) $\mathrm{Al}^{3+}-\mathrm{Az}$ complex on $\mathrm{Au}$ film and (B) $\mathrm{Az}$ on $\mathrm{Au}-\mathrm{Al}_{2} \mathrm{O}_{\mathrm{x}}$ film.

$\mathrm{Al}-\mathrm{O}$ groups exposed on the surface of $\mathrm{Al}_{2} \mathrm{O}_{\mathrm{x}}$ film and most $\mathrm{Al}^{3+}$ cations were coordinated by $6 \mathrm{O}$ atoms. Compared with the FTIR spectrum of raw Az, both two phenolic $\mathrm{C}-\mathrm{O}$ groups (1280 and $1263 \mathrm{~cm}^{-1}$ ) of $\mathrm{Az}$ occurred at larger wavenumbers (1289 and $1267 \mathrm{~cm}^{-1}$ ) in the hybrid of $\mathrm{Az}$ and $\mathrm{Au}-\mathrm{Al}_{2} \mathrm{O}_{\mathrm{x}}$ film. This demonstrates the interaction between the 1,2-dihydroxyl (catechol) and $\mathrm{Al}-\mathrm{O}$ groups (Fig. 10). Az molecules substituted the coordinated $\mathrm{O}$ on the surface, resulting in a conjugative system. 


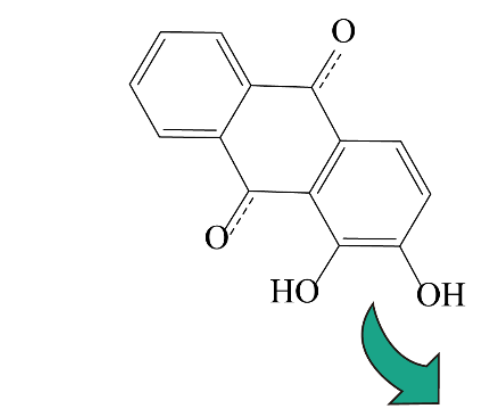

$\mathrm{H}_{2} \mathrm{O}$

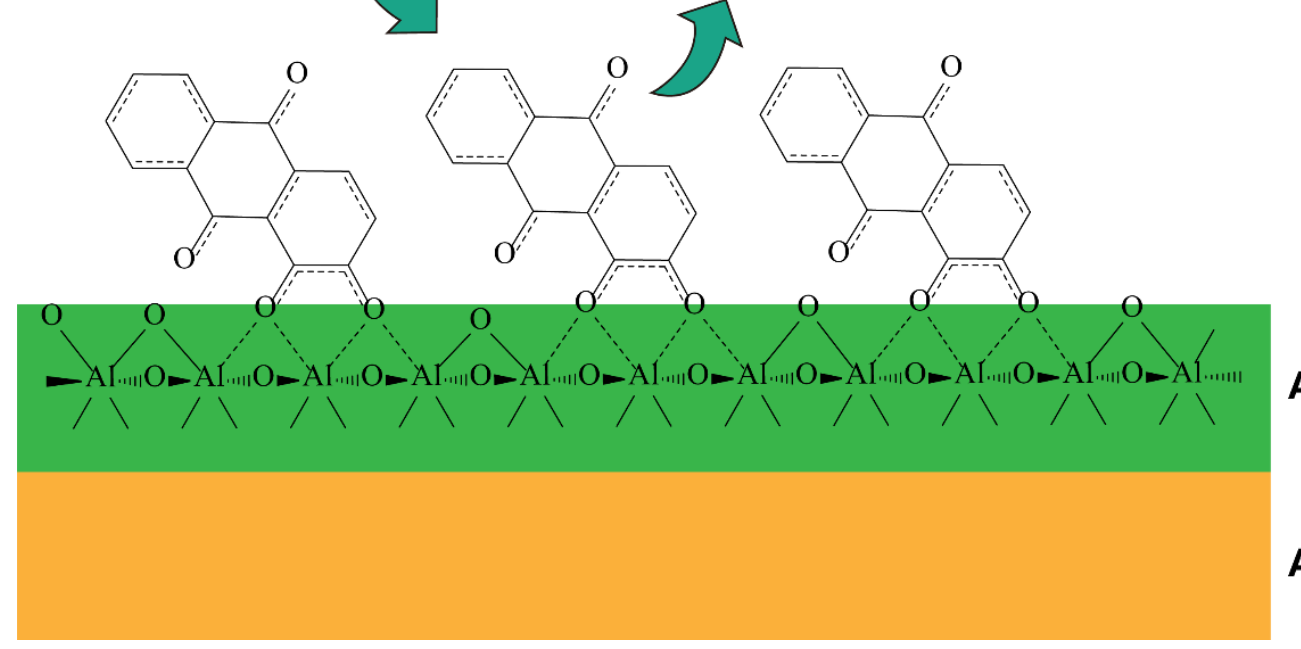

$\mathrm{Al}_{2} \mathrm{O}_{\mathrm{x}}$ film

Fig. 10 Schematically interpretive diagram of $\mathrm{Az}$ dye on the $\mathrm{Al}_{2} \mathrm{O}_{\mathrm{x}}$ film.

Au film

\subsection{Photostability}

The above results demonstrated that $\mathrm{Az}$ deposited on the $\mathrm{Au}-\mathrm{Al}_{2} \mathrm{O}_{\mathrm{x}}$ film surface showed similar interaction between $\mathrm{Al}^{3+}$ and $\mathrm{Az}$ in bulk lakes. Hence, the "film lake" can be employed to evaluate the photostability and degradation pathway. The $\mathrm{Au}-\mathrm{Al}_{2} \mathrm{O}_{\mathrm{x}}-\mathrm{Az}$ complex was exposed under UV light to evaluate the light resistance (Fig. 11). There are three changes after UV-light exposure: (i) Some new bands appeared at 1705, 1430, 1416, 1378 and $1102 \mathrm{~cm}^{-1}$ under UV light and their intensity increased with the exposure time; (ii) The bands at 1359 and $1327 \mathrm{~cm}^{-1}$, corresponding to $\delta(-\mathrm{OH})$ from phenol group decreased with the exposure time and finally disappeared; (iii) Some bands shifted to lower wavenumbers or decreased the 
intensity with the UV light exposure time increasing, i.e., a) the band at $1644 \mathrm{~cm}^{-1}$, referring to $v(\mathrm{C}=\mathrm{O})$ from $\mathrm{Az}$, shifted to $1628 \mathrm{~cm}^{-1}$, b) the band of $v(\mathrm{C}=\mathrm{C})$ from benzene ring at $1594 \mathrm{~cm}^{-1}$ shifted to $1573 \mathrm{~cm}^{-1}$ and the absorption $\mathrm{t} 1534$ and 1469 $\mathrm{cm}^{-1}$ decreased, c) the bands of $v(\mathrm{C}-\mathrm{O})$ at $\mathrm{C} 2\left(1292 \mathrm{~cm}^{-1}\right)$ and $\mathrm{C} 1\left(1264 \mathrm{~cm}^{-1}\right)$ positions decreased their intensity with the UV light exposure, and finally the signal of $\mathrm{C} 2 v(\mathrm{C}-\mathrm{O})$ disappeared, $\mathrm{d})$ the absorption bands corresponding to phenol $\delta(-\mathrm{OH})$ (1359 and $1327 \mathrm{~cm}^{-1}$ ) decreased the intensity and finally disappeared after 264-h UV light aging. We noticed that the absorption belonging to $\mathrm{Al}-\mathrm{O}-\mathrm{Al}$ group $\left(945 \mathrm{~cm}^{-1}\right)$ remained.

The new band at $1705 \mathrm{~cm}^{-1}$ indicated the presence of $\mathrm{C}=\mathrm{O}$ group under $\mathrm{UV}$ light aging. Considering the decrease and even disappearance of absorption bands referring to $v(\mathrm{C}-\mathrm{O})$, it can be concluded that $\mathrm{C}-\mathrm{O}$ groups from $\mathrm{Az}$ molecules were oxidized to $\mathrm{C}=\mathrm{O}$ groups (ketone or carboxylic acid). The decreasing intensity or even disappearance of absorption bands referring to $\mathrm{C} 1$ and $\mathrm{C} 2-\mathrm{OH}$ (phenol) groups suggested the oxidation reaction happened to the phenol groups under UV light.

Previous investigation[57] proved that $\mathrm{Az}$ was bleached by $\mathrm{H}_{2} \mathrm{O}_{2}$, which oxidized $\mathrm{Az}$ molecules from the phenol groups into ketones and finally the opening-ring reaction occurred, resulting in the generation of $\mathrm{C}=\mathrm{O}$ and $\mathrm{COOH}$ groups. The emerge of absorption at $1102 \mathrm{~cm}^{-1}$ indicated the formation of $\mathrm{Al}-\mathrm{OH}$ group. NMR results have demonstrated that $\mathrm{Az}$ anions, including $\mathrm{Az}^{-}$and $\mathrm{Az}^{2-}$, coordinated with $\mathrm{Al}^{3+}$ via catechol group. Hence, after long-time UV light exposure, the coordinated Az derivatives dissociated from the film surface due to the oxidation of Az derivatives 
(see Fig. 12). Finally, the coordination of $\mathrm{Az}$ derivatives was substituted by $-\mathrm{OH}$ group from humidity, or left the defect. The oxidation of phenol groups resulted in the change of conjugative status of Az derivatives, leading to the shifts of $v(C=C)$ from benzene ring to lower wavenumbers. 


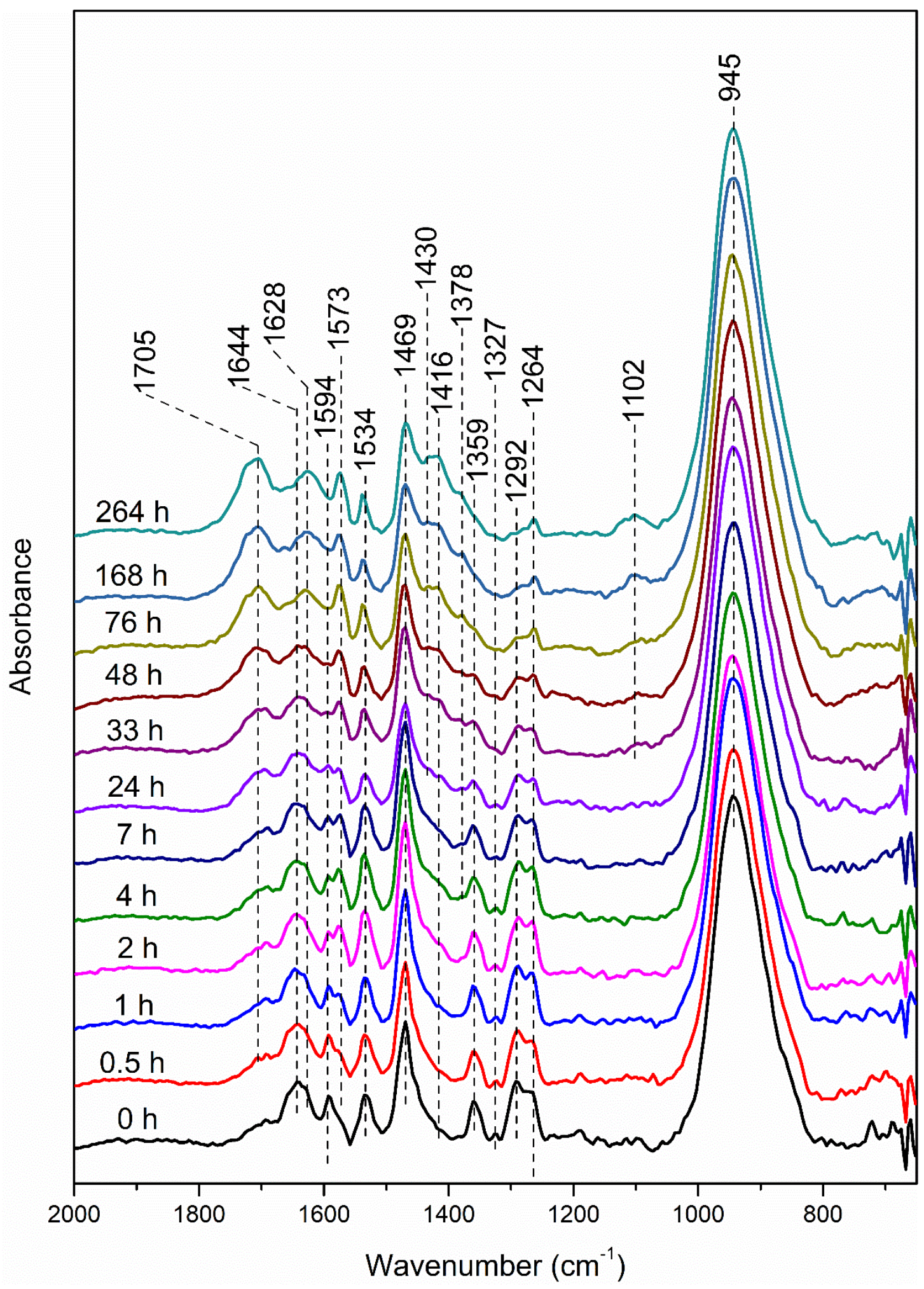

Fig. 11 PM-IRRAS spectra of UV light-aged $\mathrm{Au}-\mathrm{Al}_{2} \mathrm{O}_{\mathrm{x}}-\mathrm{Az}$ complex. 


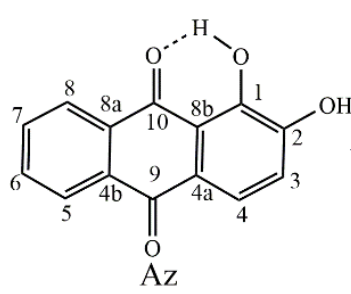<smiles>[Y20]OC(=O)c1ccccc1C1=[O+][IH]Oc2c([O-])cccc21</smiles><smiles>O=C1c2ccccc2C(=O)c2c1ccc(O)c2Cl</smiles><smiles>C=C(O)C=CC1=C(C(=O)OCCC)C(=O)c2ccccc2C1=O</smiles>
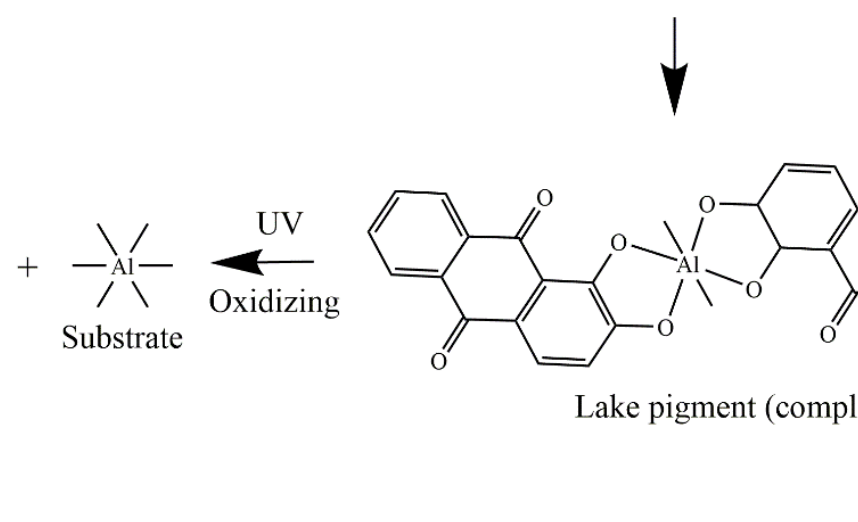

Fig. 12 The degradation pathway of Az in the lake pigments under UV light exposure. Az ionizes in water and donates protons, generating two derivatives, i.e., $\mathrm{Az}^{-}$and $\mathrm{Az}^{2-}$. The derivatives connect with $\mathrm{Al}^{3+}$, forming complexes. The Az derivatives degraded exposed under UV light by oxidizing the $\mathrm{C}-\mathrm{O}(\mathrm{H})$ into $\mathrm{COOH}$ or $\mathrm{C}=\mathrm{O}$ group, breaking the conjugative connection between $\mathrm{Az}$ derivatives and $\mathrm{Al}^{3+}$.

\section{Conclusion}

In this work, we investigated the structure and chromatic properties of non-stoichiometric $\mathrm{Al}^{3+}$-Az complexes in bulk and the interaction between $\mathrm{Az}$ and $\mathrm{Al}_{2} \mathrm{O}_{\mathrm{x}}$ film, including the degradation under UV light exposure; this was made possible by combining complementary charcaterization techniques, and adapting samples for high sensitive measurements of reactivity. Several conclusions can be drawn. (i) Az lake pigment can be synthesized at a very low concentration of Az (even with the $R=200$ ). The decrease of $R$ value only effected the lightness of lakes, 
without obvious influence on the $\mathrm{a}^{*}$ and $\mathrm{b}^{*}$ values, i.e. of the color. (ii) $\mathrm{Al}^{3+}$ formed complexes with Az derivatives by reacting with the 1,2-dihydroxyl (catechol) groups, and not with the 1-hydroxy-9-keto groups. $\mathrm{Al}^{3+}$ showed major hexa-coordination with minor penta-coordination and tetra-coordination structures. More important, the coordination between $\mathrm{Az}$ derivatives and $\mathrm{Al}^{3+}$ resulted in a conjugative system. (iii) The basic reagents, $\mathrm{K}_{2} \mathrm{CO}_{3}$ and $\mathrm{KOH}$, did not affect the color of lake pigments. But the addition of $\mathrm{KOH}$ gave rise to more coordinated $-\mathrm{OH}$ groups. (iv) Az derivatives formed conjugative complexes on the $\mathrm{Al}_{2} \mathrm{O}_{\mathrm{x}}$ film surface, similar with the bulk lakes. (v) The degradation pathway of $\mathrm{Az}$ derivatives on $\mathrm{Al}_{2} \mathrm{O}_{\mathrm{x}}$ film demonstrated the oxidation of catechol groups to carbonyl, resulting in dissociation of the conjugative system. This work presented a new insight into the structure and degradation of $\mathrm{Az}$ lake pigments. The fading of lake pigments is due to the oxidation of $\mathrm{C}-\mathrm{O}(\mathrm{H})$ groups from Az derivatives. Hence, adding some reductants or something are more sensitive to be photoexcited may be beneficial for the conservation and restoration of artworks.

\section{Acknowledgment}

The support provided by China Scholarship Council (CSC) during the visit of Guanzheng Zhuang (No. 201706400010) to Sorbonne Université is acknowledged.

\section{References}

[1] Grazia C, Clementi C, Miliani C, Romani A. Photophysical properties of alizarin and purpurin Al(III) complexes in solution and in solid state. Photochemical \& 
Photobiological Sciences. 2011;10(7):1249-54.

[2] Melo MJ, Claro A. Bright light: microspectrofluorimetry for the characterization of lake pigments and dyes in works of art. Accounts of chemical research. $2010 ; 43(6): 857-66$.

[3] Herbst W, Hunger K. Industrial organic pigments: production, properties, applications: John Wiley \& Sons, 2004.

[4] Kiel EG, Heertjes PM. Metal Complexes of Alizarin I-The Structure of the Calcium-Aluminium Lake of Alizarin. Journal of the Society of Dyers \& Colourists. $1963 ; 79(1): 21-7$.

[5] Pozzi F, van den Berg KJ, Fiedler I, Casadio F. A systematic analysis of red lake pigments in French Impressionist and Post - Impressionist paintings by surface - enhanced Raman spectroscopy (SERS). Journal of Raman Spectroscopy. 2014;45 (11-12) :1119-26.

[6] Sanyova J, Reisse J. Development of a mild method for the extraction of anthraquinones from their aluminum complexes in madder lakes prior to HPLC analysis. Journal of cultural heritage. 2006; $7(4): 229-35$.

[7] Arnold DE, Branden JR, Williams PR, Feinman GM, Brown J. The first direct evidence for the production of Maya Blue: rediscovery of a technology. antiquity. $2008 ; 82(315): 151-64$.

[8] Domenech A, Doménech-Carbó MT, del Río MS, de Agredos Pascual MLV, Lima E. Maya Blue as a nanostructured polyfunctional hybrid organic -inorganic material: the need to change paradigms. New Journal of Chemistry. 2009;33(12):2371-9.

[9] Van 01phen H. Maya blue: a clay-organic pigment? Science. 1966;154(3749):645-6. [10] Claro A, Melo MJ, de Melo JSS, van den Berg KJ, Burnstock A, Montague M, et al. Identification of red colorants in van Gogh paintings and ancient Andean textiles by microspectrofluorimetry. Journal of Cultural Heritage. 2010;11 (1):27-34.

[11] Claro A, Melo MJ, Schäfer S, de Melo JSS, Pina F, van den Berg KJ, et al. The use of microspectrofluorimetry for the characterization of lake pigments. Talanta. 2008; 74(4) : 922-9.

[12] Clementi C, Doherty B, Gentili P, Miliani C, Romani A, Brunetti B, et al. Vibrational and electronic properties of painting lakes. Applied Physics A. 2008;92 (1):25-33.

[13] Palit DK, Pal H, Mukherjee T, Mittal JP. Photodynamics of the S1 state of some hydroxy-and amino-substituted naphthoquinones and anthraquinones. Journal of the Chemical Society, Faraday Transactions. 1990;86 (23):3861-9.

[14] Karadag R, Torgan E, Yurdun T. Formation and HPLC analysis of the natural lake pigment obtained from madder (Rubia tinctorum L.). Reviews in Analytical Chemistry. $2010 ; 29(1): 1-12$.

[15] Kirby J, Spring M, Higgitt C. The technology of eighteenth-and nineteenth-century red lake pigments. National Gallery Technical Bulletin. 2007;28:69.

[16] Del Giacco T, Latterini L, Elisei F. Photophysical and photochemical properties of 1, 2, 4-trihydroxy-9, 10-anthraquinone adsorbed on inorganic oxides. Photochemical \& Photobiological Sciences. 2003;2(6):681-7.

[17] Delaney JK, Ricciardi P, Glinsman LD, Facini M, Thoury M, Palmer M, et al. Use of imaging spectroscopy, fiber optic reflectance spectroscopy, and X-ray fluorescence to map and identify pigments in illuminated manuscripts. Studies in Conservation. 
2014; $59(2): 91-101$.

[18] Fournier F, de Viguerie L, Balme S, Janot J-M, Walter P, Jaber M. Physico-chemical characterization of lake pigments based on montmorillonite and carminic acid. Appl Clay Sci. $2016 ; 130: 12-7$.

[19] Van Elslande E, Lecomte S, Le Hô AS. Micro - Raman spectroscopy (MRS) and surface - enhanced Raman scattering (SERS) on organic colourants in archaeological pigments. Journal of Raman Spectroscopy: An International Journal for Original Work in all Aspects of Raman Spectroscopy, Including Higher Order Processes, and also Brillouin and Rayleigh Scattering. 2008;39(8):1001-6.

[20] Vandenabeele P, Bodé S, Alonso A, Moens L. Raman spectroscopic analysis of the Maya wall paintings in Ek’ Balam, Mexico. Spectrochimica Acta Part A Molecular \& Biomolecular Spectroscopy. 2005;61 (10):2349-56.

[21] Clementi C, Nowik W, Romani A, Cibin F, Favaro G. A spectrometric and chromatographic approach to the study of ageing of madder (Rubia tinctorum L. ) dyestuff on wool. Analytica chimica acta. 2007;596(1):46-54.

[22] Saunders D, Kirby J. Light-induced colour changes in red and yellow lake pigments. National Gallery Technical Bulletin. 1994;15(1):79-97.

[23] Favaro G, Miliani C, Romani A, Vagnini M. Role of protolytic interactions in photo-aging processes of carminic acid and carminic lake in solution and painted layers. Journal of the Chemical Society, Perkin Transactions 2. $2002(1): 192-7$.

[24] Feller RL, Johnston-Feller RM, Bailie C. Determination of the Specific Rate Constant for the Loss of a Yellow Intermediate during the Fading of Alizarin Lake. Journal of the American Institute for Conservation. 1986;25(2):65-72.

[25] Weiser HB. The Physical Chemistry of Color Lake Formation. V. Hydrous 0xide Alizarin Lakes. Jphyschem. 1928;33(5):1713-23.

[26] Weiser HB, Porter EE. The Physical Chemistry of Color Lake Formation. II. Adsorption of Typical Dyes by Basic Mordants. Jphyschem. 1926;31(11):1704-15.

[27] Weiser HB, Porter EE. The Physical Chemistry of Color Lake Formation. III. Alizarin Lakes. Journal of Physical Chemistry. 1927;31 (12):1824-39.

[28] Kiel EG, Heertjes PM. Metal Complexes of Alizarin II-The Structure of Some Metal Complexes of Alizarin other than Turkey Red. Journal of the Society of Dyers \& Colourists. $1963 ; 79(2): 61-4$.

[29] Kiel EG, Heertjes PM. Metal Complexes of Alizarin III-The Structure of Metal Complexes of some 3-Derivatives of Alizarin. Journal of the Society of Dyers \& Colourists. $1963 ; 79(5): 186-8$.

[30] Kiel EG, Heertjes PM. Metal Complexes of Alizarin IV-The Structure of the Potassium and Calcium Salts of Alizarin and of 3 - Nitroalizarin. Journal of the Society of Dyers \& Colourists. $1963 ; 79(8): 363-7$.

[31] Komiha N, Kabbaj 0, Chraibi M. A density functional study of alizarin two of its isomers and its transition metals and rare-earth complexes. Journal of Molecular Structure: THEOCHEM. 2002;594(3):135-45.

[32] Soubayrol P, Dana G, Man PP. Aluminium - 27 Solid - State NMR Study of Aluminium Coordination Complexes of Alizarin. Magnetic resonance in chemistry. 1996;34 (8):638-45. [33] Fain VY, Zaitsev B, Ryabov M. Metal complexes with alizarin and alizarin red S: 
Electronic absorption spectra and structure of ligands. Russian Journal of Coordination Chemistry. 2004;30(5):365-70.

[34] Doskocz M, Kubas K, Frąckowiak A, Gancarz R. NMR and ab initio studies of Mg2+, Ca2+, Zn2+, Cu2+ alizarin complexes. Polyhedron. 2009;28(11):2201-5.

[35] Wunderlich CH, Bergerhoff G. Konstitution und Farbe von Alizarin - und Purpurin - Farblacken. Chemische Berichte. 1994;127(7):1185-90.

[36] Sanyova J. Contribution à l'étude de la structure et des propriétés des laques de garance. 2001.

[37] Sanyova J. Spectroscopic studies (FTIR, SIMS, ES-MS) on the structure of Anthraquinone-Aluminium complexes. In: Kirby J, editor. Dyes in history and archaeology 21. London: Archetype Publications Ltd; 2008. p. 208-13.

[38] Dworak L, Matylitsky VV, Wachtveitl J. Ultrafast Photoinduced Processes in Alizarin - Sensitized Metal 0xide Mesoporous Films. ChemPhysChem. 2009;10(2):384-91.

[39] Whitney AV, Elam JW, Zou S, Zinovev AV, Stair PC, Schatz GC, et al. Localized surface plasmon resonance nanosensor: a high-resolution distance-dependence study using atomic layer deposition. The Journal of Physical Chemistry B. 2005;109(43):20522-8.

[40] Zhang X, Zhao J, Whitney AV, Elam JW, Van Duyne RP. Ultrastable substrates for surface-enhanced Raman spectroscopy: A1203 overlayers fabricated by atomic layer deposition yield improved anthrax biomarker detection. Journal of the American Chemical Society. 2006;128 (31) : 10304-9.

[41] Bonnelle C, Vergand F, Jonnard P, André JM, Staub P, Avila P, et al. Instrument for research on interfaces and surfaces. Review of Scientific Instruments. $1994 ; 65$ (11) : 3466-71.

[42] Koperska M, Łojewski T, Łojewska J. Vibrational spectroscopy to study degradation of natural dyes. Assessment of oxygen-free cassette for safe exposition of artefacts. Analytical and bioanalytical chemistry. 2011;399 (9):3271-83.

[43] Pérez E, Ibarra IA, Guzmán A, Lima E. Hybrid pigments resulting from several guest dyes onto $\gamma$-alumina host: A spectroscopic analysis. Spectrochimica Acta Part A: Molecular and Biomolecular Spectroscopy. 2017;172:174-81.

[44] Farmer VC. Infrared spectra of minerals: Mineralogical society, 1974.

[45] Buining PA, Pathmamanoharan C, Jansen JBH, Lekkerkerker HN. Preparation of colloidal boehmite needles by hydrothermal treatment of aluminum alkoxide precursors. Journal of the American Ceramic Society. 1991;74(6):1303-7.

[46] Frost RL, Kloprogge JT, Russell SC, Szetu J. Dehydroxylation of aluminum (oxo) hydroxides using infrared emission spectroscopy. Part II: Boehmite. Applied Spectroscopy. 1999;53(5):572-82.

[47] Kirby J, Spring M, Higgitt C. The technology of red lake pigment manufacture: study of the dyestuff substrate. National Gallery Technical Bulletin. 2005;26:71-87.

[48] Chen XY, Huh HS, Lee SW. Hydrothermal synthesis of boehmite $(\gamma-\mathrm{AlO0H})$ nanoplatelets and nanowires: pH-controlled morphologies. Nanotechnology. 2007;18 (28) :285608.

[49] Hou H, Xie Y, Yang Q, Guo Q, Tan C. Preparation and characterization of $\gamma-\mathrm{AlOOH}$ nanotubes and nanorods. Nanotechnology. 2005;16 (6) :741.

[50] Tsuchida T, Ichikawa N. Mechanochemical phenomena of gibbsite, bayerite and boehmite by grinding. Reactivity of Solids. 1989;7(3):207-17. 
[51] Wang S-L, Johnston CT. Assignment of the structural OH stretching bands of gibbsite. American Mineralogist. 2000;85 (5-6):739-44.

[52] Zenobi MC, Luengo CV, Avena MJ, Rueda EH. An ATR-FTIR study of different phosphonic acids adsorbed onto boehmite. Spectrochimica Acta Part A: Molecular and Biomolecular Spectroscopy. $2010 ; 75(4): 1283-8$.

[53] Brus J, Abbrent S, Kobera L, Urbanova M, Cuba P. Advances in 27A1 MAS NMR studies of geopolymers. Annual reports on NMR spectroscopy: Elsevier; 2016. p. 79-147.

[54] Gooch JW. Alizarin Madder Lake: Springer New York, 2011.

[55] Say-Liang-Fat S, Cornard J-P. Al (III) complexation by alizarin studied by electronic spectroscopy and quantum chemical calculations. Polyhedron. $2011 ; 30(13): 2326-32$.

[56] Bilgic D, Karaderi S, Bapli I. The Determination of the Stability Constants Binary Complexes of Alizarin with Ca (II) and Zn (II) by Potentiometrie and Spectrophotometric Methods. Reviews in Analytical Chemistry. 2007;26(2):99-108.

[57] Thompson KM, Griffith WP, Spiro M. Mechanism of bleaching by peroxides. Part 2. - Kinetics of bleaching of alizarin and crocetin by hydrogen peroxide at high $\mathrm{pH}$. Journal of the Chemical Society, Faraday Transactions. 1993;89(22) :4035-43. 